\title{
The social modulation of pain: others as predictive signals of salience - a systematic review
}

\author{
Charlotte Krahé ${ }^{1}$, Anne Springer ${ }^{2}$, John A. Weinman ${ }^{1}$ and Aikaterini Fotopoulou ${ }^{3}$ * \\ 1 Department of Psychology, Institute of Psychiatry, King's College London, London, UK \\ ${ }^{2}$ Department of Sport and Exercise Psychology, University of Potsdam, Potsdam, Germany \\ ${ }^{3}$ Research Department of Clinical, Educational and Health Psychology, University College London, London, UK
}

Edited by:

Diana M. E. Torta, University of Turin, Italy

\section{Reviewed by:}

Stephanie D. Preston, University of

Michigan, USA

Matthew R. Longo, Birkbeck

University of London, UK

*Correspondence:

Aikaterini Fotopoulou, Research Department of Clinical, Educational and Health Psychology, University College London, Gower Street, London WC1E 6BT, UK e-mail: a.fotopoulou@ucl.ac.uk
Several studies in cognitive neuroscience have investigated the cognitive and affective modulation of pain. By contrast, fewer studies have focused on the social modulation of pain, despite a plethora of relevant clinical findings. Here we present the first review of experimental studies addressing how interpersonal factors, such as the presence, behavior, and spatial proximity of an observer, modulate pain. Based on a systematic literature search, we identified 26 studies on experimentally induced pain that manipulated different interpersonal variables and measured behavioral, physiological, and neural pain-related responses. We observed that the modulation of pain by interpersonal factors depended on (1) the degree to which the social partners were active or were perceived by the participants to possess possibility for action; (2) the degree to which participants could perceive the specific intentions of the social partners; (3) the type of pre-existing relationship between the social partner and the person in pain, and lastly, (4) individual differences in relating to others and coping styles. Based on these findings, we propose that the modulation of pain by social factors can be fruitfully understood in relation to a recent predictive coding model, the free energy framework, particularly as applied to interoception and social cognition. Specifically, we argue that interpersonal interactions during pain may function as social, predictive signals of contextual threat or safety and as such influence the salience of noxious stimuli. The perception of such interpersonal interactions may in turn depend on (a) prior beliefs about interpersonal relating and (b) the certainty or precision by which an interpersonal interaction may predict environmental threat or safety.

Keywords: pain, social modulation, social support, empathy, predictive coding, attachment, review

\section{INTRODUCTION}

Pain is a subjective psychological state which acts as an indicator of threat to the organism in association with actual or potential tissue damage (IASP, 1994). Pain is multidimensional, including unpleasant feelings (interoception; Craig, 2002) and sensations (nociception) about the state of the organism, as well as motivated behaviors, such as withdrawing from a noxious stimulus. Several studies in cognitive neuroscience have investigated the cognitive and affective modulation of pain (e.g., Tracey et al., 2002). For example, attention (e.g., Villemure and Bushnell, 2002), mood (e.g., Yoshino et al., 2010), and cognitive appraisals (e.g., Vlaeyen et al., 2009) have been found to modulate pain. By contrast, the modulation of pain by social factors has received far less experimental and neuroscientific attention to date. This is despite a plethora of clinical, correlational findings pointing to associations between pain and the social context in which it occurs (Leonard et al., 2006).

Close relationships are beneficial to both mental and physical health, including stress and pain. For example, a wealth of research has shown that support from others is linked to beneficial effects on physiological and psychological well-being (Uchino et al., 1996; Blasi et al., 2001; Kikusui et al., 2006), while social isolation and poor quality relationships are detrimental to health (House et al.,
1988). However, support from others is not a panacea; rather, the effects of social support on health, such as stress and pain, depend on the facet of social support studied (e.g., Schaefer et al., 1981; Barrera, 1986) and on factors such as gender or relationship characteristics (Kirschbaum et al., 1995; Hennessy et al., 2009).

A similar picture emerges when studying social influences on pain. While there has been much research in clinical populations (e.g., Penner et al., 2008; Williams et al., 2011) and chronic pain populations more specifically (see below for a brief review), fewer studies have experimentally investigated the role of social context on pain in healthy individuals. Although clinical pain differs from experimentally induced pain (McGrath, 1983), studies in the latter tradition are indispensable for elucidating causal influencing factors because they allow controlled manipulation of the social variables of interest. Interestingly, such experimental manipulations reveal that multidimensional concepts such as social support may not be sufficient to characterize the social modulation of pain. Rather, particular facets of the social context seem to differentially influence whether and how interpersonal interactions can affect pain. Thus, this diversity and the specific causal mechanisms by which different social factors influence pain warrant systematic consideration. Unfortunately, to the best of our knowledge, there is no systematic review of these studies. Accordingly, the present 
paper aimed to provide a systematic review of studies that experimentally investigated the effects of interpersonal factors on pain with a focus on discovering the underlying causal mechanisms.

In addition, we aimed to use a framework from computational neuroscience, namely the free energy framework as applied to interoception (Seth et al., 2012) and social cognition (Brown and Brüne, 2012), as the theoretical basis for the integration and understanding of the findings presented in this review. Several perspectives exist which view pain (Sullivan et al., 2001; Craig, 2009a) and emotion more generally (Griffiths and Scarantino, 2009; Van Kleef, 2009; Coan, 2011) as embedded within a social context and posit mechanisms by which social partners affect an individual's experience (e.g., by providing support or contextual information). Adding to these, we believe a predictive coding scheme, such as the free energy framework (see below), to be particularly promising because it provides a unifying, neurobiologically plausible account of the integration of different hierarchical levels of processing, from nociception to social cognition. It can thus shed light on the mechanisms by which interpersonal factors affect pain-related perceptions and actions. Furthermore, this framework places emphasis on how pre-existing mental models shape current perception and action at different time scales. This focus is consistent with the pain literature under consideration, which has long stressed the pivotal role influence of anticipatory cognitions and emotions on pain (e.g., Wiech et al., 2010), as well as the corresponding social literature that has underlined the role of pre-learned social relating schemas in subsequent perceptions and reactions (Meredith et al., 2006).

Bayesian predictive coding models such as the free energy framework are powerful theoretical and neurobiological models of perception and action (Dayan and Hinton, 1996; Rao and Ballard, 1999; Schultz and Dickinson, 2000). The essence of these models is that neurobiological message-passing in the brain is achieved by coding potentially ambiguous (noisy) incoming information in light of prior expectations about the likely sensory causes of such information. Further, the related hypotheses ("generative models") of the hidden causes of sensory input are constantly updated on the basis of mismatches between expectation and experience ("prediction errors," also conceptualized as free energy), and optimized so as to minimize prediction error. While the above describes perceptual inference, the free energy framework includes a parallel process of active inference, which entails acting on the environment to change sensory input and also leads to the optimization of prediction errors (Friston et al., 2012). In general terms, prediction errors are assumed to be conveyed by feed-forward connections from lower to higher neural levels to improve representations in the latter, and higher-order predictions are transferred via feedback connections that can suppress prediction errors in lower levels. The reciprocal but asymmetric characteristics of this hierarchy (see also Mesulam, 2012) allow for an optimization that makes every level accountable to the others, delivering an internally consistent re-representation of sensory causes at multiple levels of the neurocognitive hierarchy.

Unfortunately, most psychological models based on the free energy framework concern exteroception (the perception of the environment or the self via, e.g., vision and hearing) and proprioception (the sense of the position of the body in space). Only very recently, a predictive coding model of interoceptive awareness has been proposed, describing subjective feeling states as arising from predictive inferences on the causes of interoceptive signals (Seth et al., 2012). With regard to pain, such a model is highly relevant because pain has recently been re-classified as an interoceptive modality (Craig, 2002, 2009b). Interoception in this renewed sense does not refer only to visceral sensation but to the central processing of all homeostatic afferent activity that can reflect the various components of the physiological condition of the body. In this view, pain and all feelings from the body are processed peripherally and centrally by a recently discovered lamina I spinothalamocortical pathway that projects to the posterior granular and mid-dysgranular regions of the insular cortex (serving as primary interoceptive cortex) via the brainstem parabrachial nucleus and posterior part of the ventromedial thalamic nuclei (Craig, 2003, 2009b). Primary interoceptive signals are thought to be represented in the $\mathrm{mid} /$ posterior insula, where they are also integrated with exteroceptive information coming from different brain areas. Further re-mappings within the anterior insula, the anterior cingulate cortex (ACC), and the orbitofrontal cortex are thought to consolidate body-state signals with social, motivational, and contextual information to ultimately give rise to the conscious experience of emotions, as well as to prepare the organism for the necessary action in the environment (Damasio et al., 2000; Craig, 2002, 2009b; Critchley, 2005).

A number of recent neuroimaging studies have included such areas and their observed functional connectivity in various hypothesized "salience networks" (Seeley et al., 2007; Medford and Critchley, 2010; Wiech et al., 2010; Legrain et al., 2011; Cauda et al., 2012). For instance, predictive signals from such a "salience network" process and integrate information about the significance of an impending noxious stimulus and determine whether or not such a stimulus will be consciously perceived as painful (Wiech et al., 2010), and indeed the insula cortex responds to interoceptive stimuli on the basis of expectations (Seth et al., 2012). Thus, the neural regions involved in interoception generate predictive signals of interoceptive salience. Pain can therefore constitute a process of perceptual inference about nociceptive signals on the basis of predictive, top-down signals about the homeostatic significance of such signals in the context of other synchronous biological, cognitive, and social conditions.

Furthermore, such re-mappings of interoceptive signals across the neurocognitive hierarchy suggest possible neurobiological mechanisms by which not only cognitive, but also social contextual factors can influence the awareness of interoceptive and other multimodal information about one's own body. In pain research, it is established that nociception ("the neural process of encoding noxious stimuli"; IASP, 1994) is not sufficient to explain the conscious experience of pain (e.g., Hofbauer et al., 2004; Baumgärtner et al., 2006; Nikolajsen and Jensen, 2006; Lee et al., 2009), and it has been repeatedly demonstrated that psychosocial factors can have important top-down effects on pain (e.g., the studies discussed in the present review). Thus, the application of the free energy framework to pain may be particularly fruitful to generate organized accounts of the dynamic relations between bottom-up (e.g., nociception) and top-down (e.g., psychosocial) influences on pain. In addition, pain engenders action, e.g., it motivates 
behaviors designed to ensure the organism is no longer under threat (Auvray et al., 2010; Wiech and Tracey, 2013). Hence, perceptual and motivational aspects of pain can be unified under the same optimization principle within a free energy framework. In particular, the motivational aspects of pain can be conceptualized as a process of active inference, where actions are performed to change nociceptive input and update predictions. In a social context, such actions may elicit help from others and change sensations via this social channel.

In the following, we explain the inclusion criteria and methods applied to our review (see Method), present the results (see Results and their Organization) and place these findings in the broader context of the free energy framework introduced above (see Discussion) to illustrate how interpersonal interactions may be integrated at different neural levels to influence the perception of pain and related behavioral responses. Before turning to these sections, we briefly consider two other research traditions, namely studies on the social modulation of clinical chronic pain, and pain in animals. While these traditions fall outside the remit of this review, we consider it important to briefly summarize their main findings as an introduction to the potential psychological and neurobiological mechanisms that may mediate the social modulation of pain in healthy human populations (see also, e.g., Payne and Norfleet, 1986; Newton-John, 2002; Cano, 2004; Panksepp, 2006; Cano et al., 2008; Mogil, 2009, respectively).

\section{INSIGHTS FROM CLINICAL STUDIES}

In clinical pain populations, a wealth of research has focused on the role of social support in chronic pain, and on the relationship between the pain patient and their partner (e.g., Block, 1981; Flor et al., 1987; Boothby et al., 2004; Cano et al., 2005). While some studies report correlations between perceived social support and lower pain intensity (López-Martínez et al., 2008), others have found a positive association between social support and pain behaviors (e.g., Gil et al., 1987), level of pain (Flor et al., 1987; Kerns et al., 1990), and disability (Romano et al., 1995). The majority of research has drawn on behavioral models to explain these associations, focusing strongly on operant conditioning (Cano and Williams, 2010). The operant conditioning perspective posits that repeated instances of social support serve to reward or punish pain behaviors, leading to positive or negative reinforcement of such behaviors. While this model has been broadly supported, also in an experimental study (Jolliffe and Nicholas, 2004), it does not include cognitive and affective factors and thus may not offer a complete picture of the complexity of social interactions (NewtonJohn, 2002). Cognitive-behavioral models focusing more on pain appraisals have emerged. One prominent example is the communal coping model of pain catastrophizing (e.g., Sullivan et al., 2001), which claims that individuals who tend to catastrophize that is, exaggerate the threat value of pain and see themselves as unable to cope with pain themselves (Keefe et al., 2000) - might engage in more pain behaviors to attract support from others. Here, pain appraisals play a key role in the social context of pain. A further perspective integrating cognitive factors and placing them within a relationship context is the intimacy model (see Cano and Williams, 2010), in which communicating pain to a partner is viewed as an attempt to create and maintain an emotionally intimate relationship environment.
In sum, clinical pain studies, although correlational in nature, have led to the development of several models which have been adapted to experimental settings (e.g., Sullivan et al., 2004). Furthermore, clinical studies investigate long-term pain, in which pain appraisals may be more strongly established than in the transient context of experimental settings. As many chronic pain studies focus on the partner as supportive other, they also address the importance of the relationship between supportive other and pain patient. Thus, their findings are important in fostering our understanding of psychological mechanisms underlying the social modulation of pain in humans.

\section{INSIGHTS FROM ANIMAL STUDIES AND IMPLICATIONS FOR HUMAN RESEARCH}

Although direct comparisons between human and animal studies are not warranted, animal studies can provide tentative neurobiological insights into the social modulation of pain. Animals and particularly mammals are highly sociable, and many animals including humans - rely on parental care for survival in early life. To regulate proximity to these critical caregivers, animals and humans possess an attachment system which manifests itself in the formation of close social bonds (Panksepp, 1998). Several studies have investigated whether such social bonds influence pain in animals, typically by studying the behavior of mouse dyads while pain is induced in one dyad member. Langford and colleagues found that female mice approaching a dyad member in pain led to less writhing from the mouse in pain. Crucially, these beneficial effects of social contact were seen only when the approaching mouse was a cagemate of the mouse in pain rather than a stranger (Langford et al., 2010). In this vein, D'Amato and Pavone (1993) discovered that interacting with siblings reduced pain sensitivity in mice, whilst interacting with stranger mice did not. In addition to establishing that close social relationships modulate pain in mice, these studies have also shed light on possible underlying neurobiological mechanisms. Specifically, endogenous opioids and oxytocin have been implicated, the former relating to reinforcement of social emotions (D'Amato and Pavone, 1993) and the latter playing an important role in social bonding (for a review, see Campbell, 2010). Regarding endogenous opioids, D'Amato and Pavone found that their socially induced analgesic effects were blocked when mice received naloxone, an opioid antagonist, pointing to a mediating role of endogenous opioids. Oxytocin has been linked to pain reduction per se (Yu et al., 2003) and interacts with opioid and also dopaminergic systems, with dopamine driving the motivation to affiliate and form social bonds (McCall and Singer, 2012). Furthermore, oxytocin exerts positive effects such as preventing the development of depressive-like behavior in socially isolated mice with nerve damage (Norman et al., 2010). Therefore, these proposed neurobiological mechanisms seem to relate both to social bonding and pain.

Indeed, similarities between pain and social loss have been observed in animals (Panksepp et al., 1997): both pain and social experiences include threat, unpleasantness, and loss (e.g., of a function or fellow animal) in phenomenological terms, and from a neurological viewpoint, opioid administration seems to alleviate both bodily pain and the pain of social isolation/absence of a caregiver. In light of these similarities, Panksepp and colleagues proposed that the drive to seek proximity and avoid separation 
is built upon the foundations of the older pain system (including, e.g., the opioid system); thus, social loss or separation hurts. Though caution is necessary when making comparisons between animals and humans, the neural links between pain and the distress of social loss have been investigated in humans.

In humans, higher baseline pain sensitivity has been linked to greater distress following social rejection, and heightened levels of social distress have been associated with more pain unpleasantness on thermal pain induction following social rejection (Eisenberger et al., 2006). Functional neuroimaging studies have suggested that similar neural regions to those implicated in bodily pain are activated during social pain (e.g., the dorsal ACC; Eisenberger et al., 2003; Eisenberger, 2012) though whether these regions are painspecific is debated (e.g., Legrain et al., 2011; Mouraux et al., 2011). Taken together, these studies propose tentative neural mechanisms involved in the social modulation of pain and social connection in animals and as well as humans and underline the importance of close attachment bonds.

\section{METHOD}

\section{SELECTION OF STUDIES}

We conducted a systematic search of the on-line databases Web of Knowledge, PubMed, PsycInfo, and Google Scholar, using combinations of the following keywords: "pain," "interpersonal," "empathy," "attachment," “social context," "social interaction," "social support," "social presence," and "social modulation." Reference lists of relevant articles were also searched. The results were assessed for inclusion using the publication title and abstract. No restrictions regarding publication dates were applied.

Studies were included if they conformed to the following five a priori inclusion and exclusion criteria. Firstly, we excluded wider societal (intergroup) influences. Naturally, pain is generally experienced within the wider social world, and gender (e.g., Levine and De Simone, 1991), ethnicity (e.g., Weisse et al., 2005), and ingroup/out-group influences (Buss and Portnoy, 1967), to name but a few, undoubtedly contribute to the social modulation of pain. However, we focused our review on experimental studies examining interpersonal influences rather than the larger social context of pain to advance our understanding of the causal interpersonal mechanisms that may shape an individual's pain experience. Specifically, we included those studies which manipulated an embodied or primed interpersonal exchange "between two or more individuals which is very largely determined by their individual characteristics and the nature of the personal relations between them" (the interpersonal extreme, Tajfel, 1982, p.13) and excluded "interactions which are largely determined by group memberships of the participants and very little - if at all - by their personal relations or individual characteristics" (the intergroup extreme, Tajfel, 1982, p.13). Hence, we excluded studies that varied, for example, experimenter gender or race, unless they also manipulated aspects of an interpersonal interaction. We also excluded social modeling studies in which both interaction partners received pain (or were made to believe the other received pain). Consistent with the tradition of studies addressing social support, our focus was on how the person in pain was affected by interpersonal interactions with pain-free individuals.

Secondly, studies were included if they experimentally induced pain (e.g., by means of a coldpressor task) and excluded if they used clinical procedures such as routine immunizations. We excluded clinical procedures because they differed from laboratory studies in the use of health-related procedures (which implicate additional variables such as illness perceptions, medical history etc.) and in the degree of experimental control (for a discussion, see Manimala et al., 2000). Thirdly, related to the previous point, studies were included if they examined the causal effects of interpersonal interactions on pain and were excluded if they merely correlated pain data with social variables. Fourthly, studies were included if they reported behavioral pain outcomes (e.g., pain intensity ratings, facial expressions) or pain-related physiological outcomes. To render studies comparable, neuroimaging studies were only included if they also yielded behavioral or physiological data. Finally, studies were included if they were published in English.

\section{RESULTS AND THEIR ORGANIZATION}

Twenty-six studies met the above five inclusion criteria. A summary of included studies is presented in Table 1. The terms "participant" and "person in pain" refer to the individual receiving pain, while "social partner" denotes the individual interacting with the person in pain, e.g., providing support. A variety of terms have been used in the literature in relation to the social modulation of pain, including "social support," "social interaction," "interpersonal interaction," "social presence," "social influence," and "social context." Each of these terms appears to place a slightly different emphasis on the social partner; for example, "social support" implies a directly caring attitude toward the person in pain compared to the broader term "social context." For the purposes of our analysis, we used the term "social context" when discussing the role of others generally and "interpersonal interaction" when discussing specific interactions between social partner and participant in pain as outlined above.

Due to the large variety in pain measures obtained across studies, we summarized and presented pain measures in five sub-categories in the table. (1) "Pain ratings" refers to participant-generated ratings, e.g., of pain intensity, unpleasantness, or pain threshold; (2) "pain behaviors" denotes painrelated behaviors such as pain tolerance or facial expressions; (3) "pain words" refers to pain-related verbalizations to the social partner; (4) "physiological measures" pertains to measures of heart rate, skin conductance levels, blood pressure, etc.; and (5) "neural activity" signifies magnetoencephalography (MEG), and blood-oxygen-level-dependent (BOLD) measures obtained from functional magnetic resonance imaging (fMRI). Further, only findings relating to the above pain outcome measures were included in the table and additional variables such as gender or catastrophizing were included only if they interacted with the social manipulation in affecting pain. We address methodological issues where relevant in the results section.

The studies meeting the inclusion criteria were based in different research and theoretical traditions (e.g., health sciences, social psychology, clinical psychology, and social cognitive neuroscience). To ensure valid comparisons between studies, the theoretical context of such concepts, their taxonomy, and precise operationalization in each study were addressed when appropriate in the following sections, and they were taken into account when reviewing and integrating the data. 


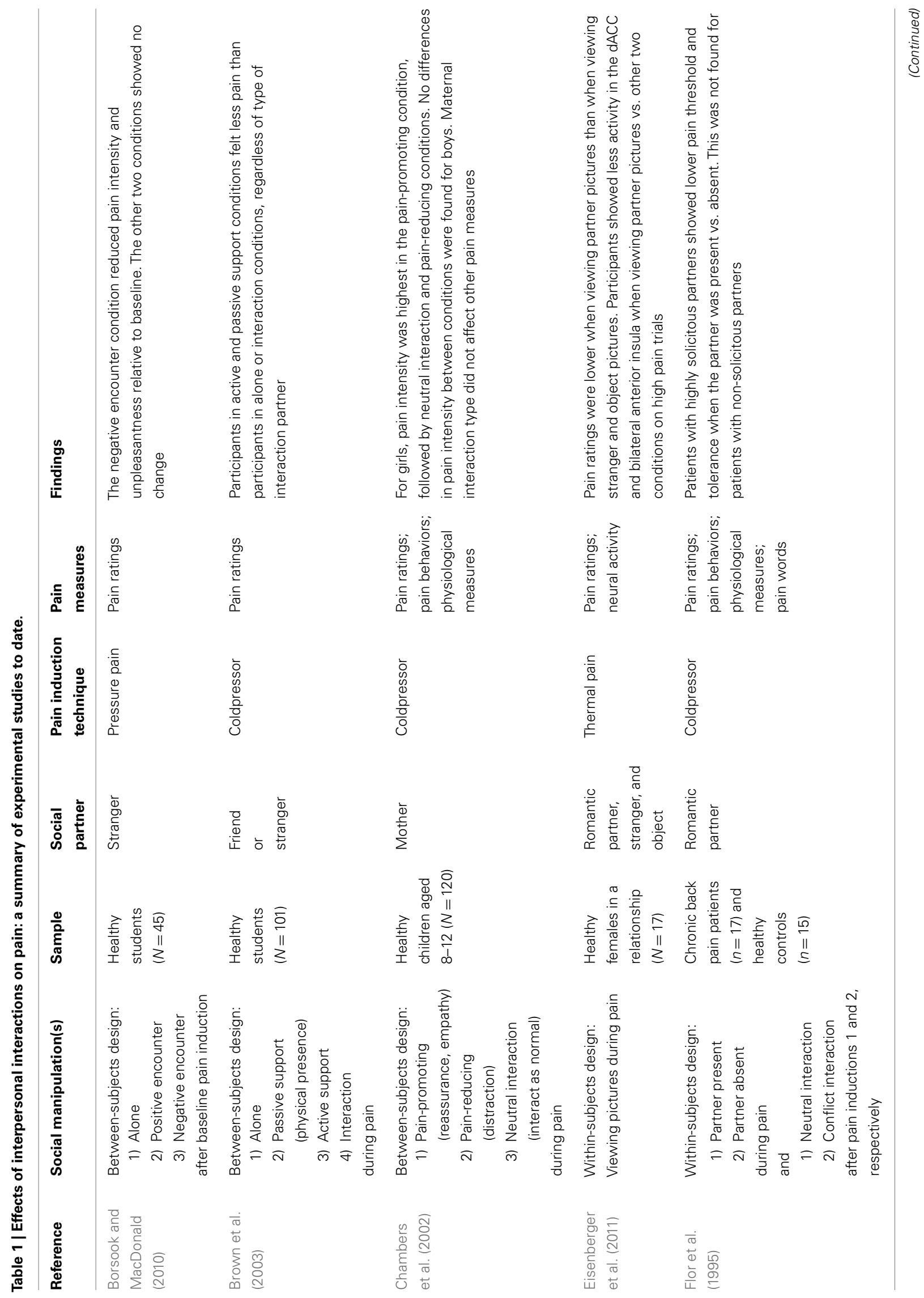



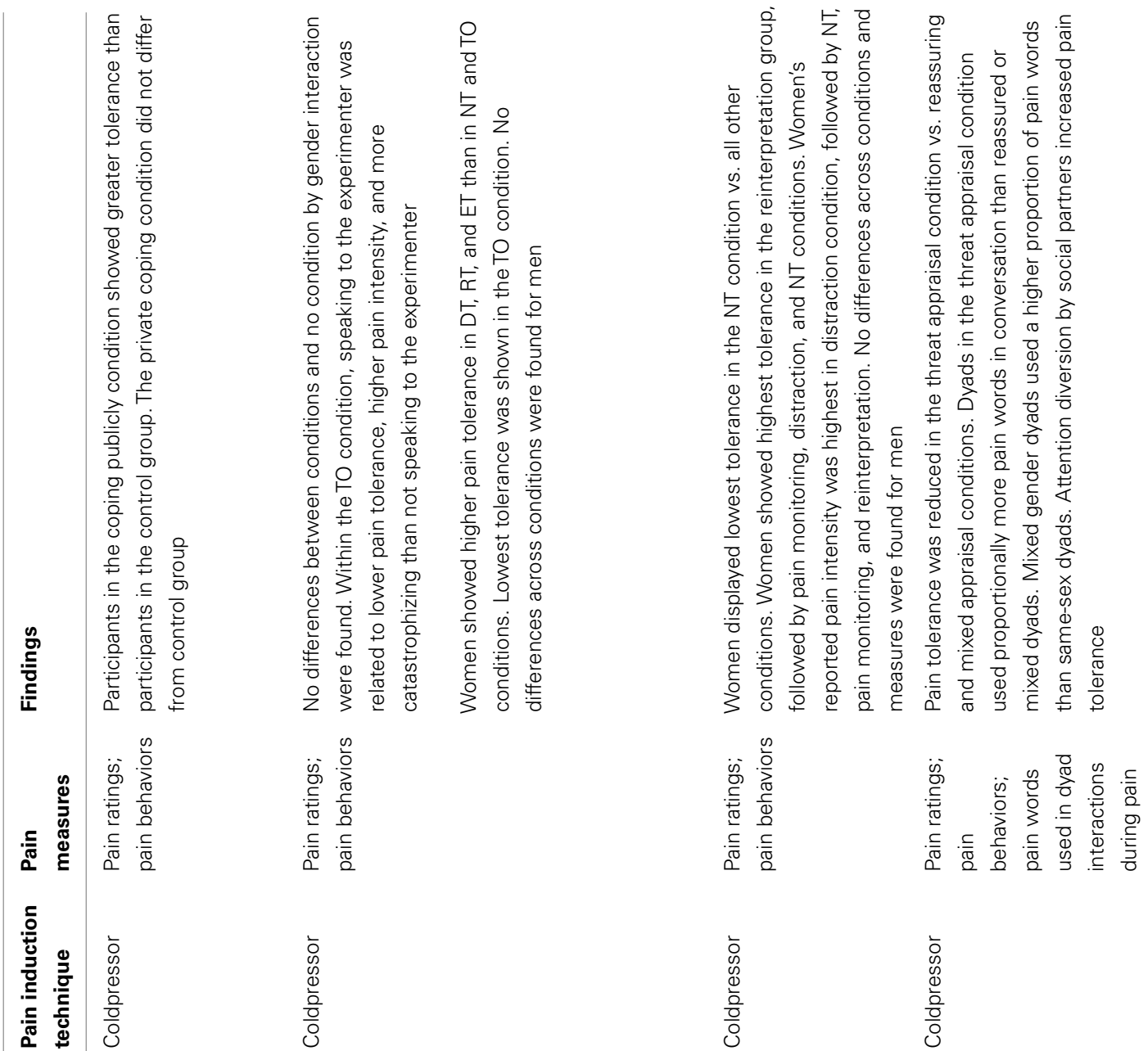

$\grave{o}$
0
0
0
$\frac{0}{0}$
$\overline{0}$
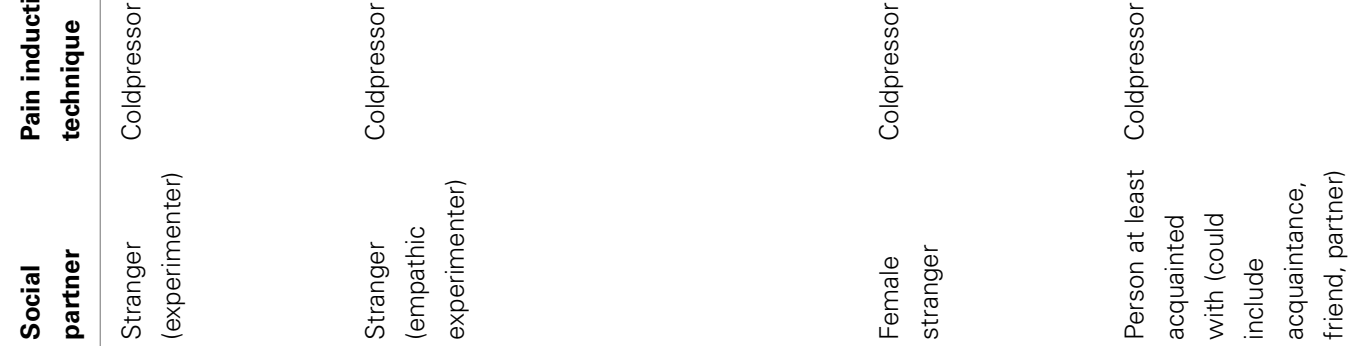

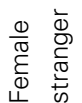

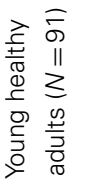
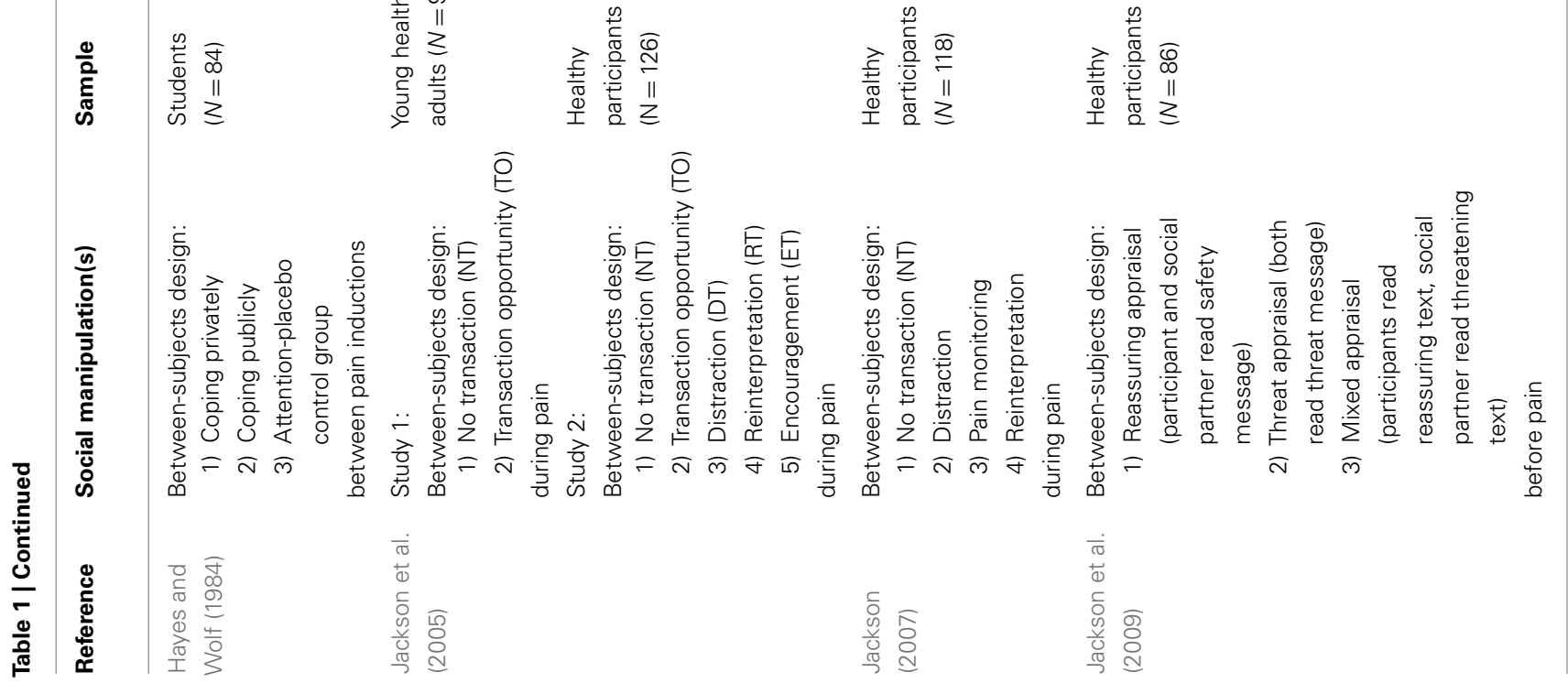


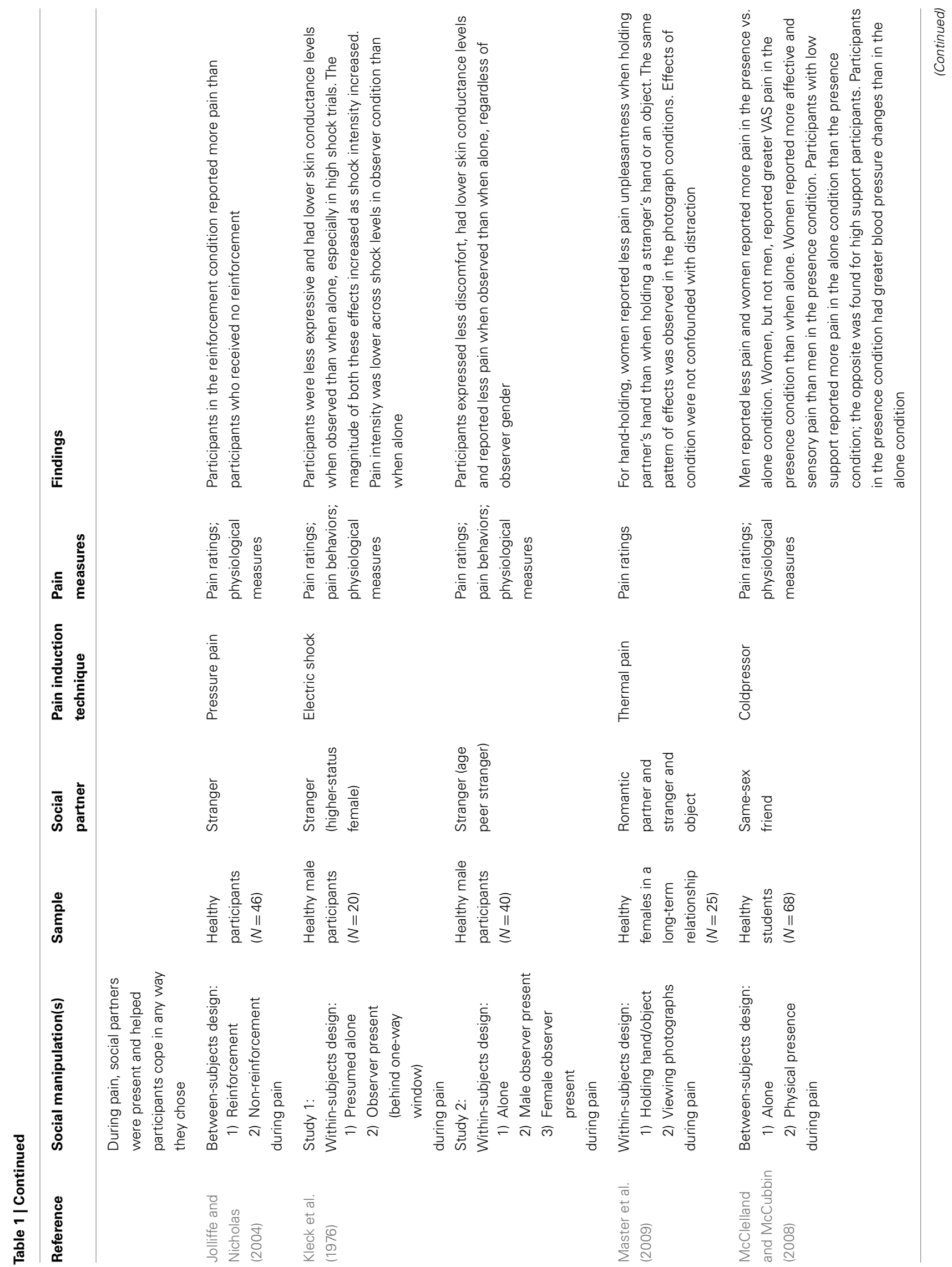




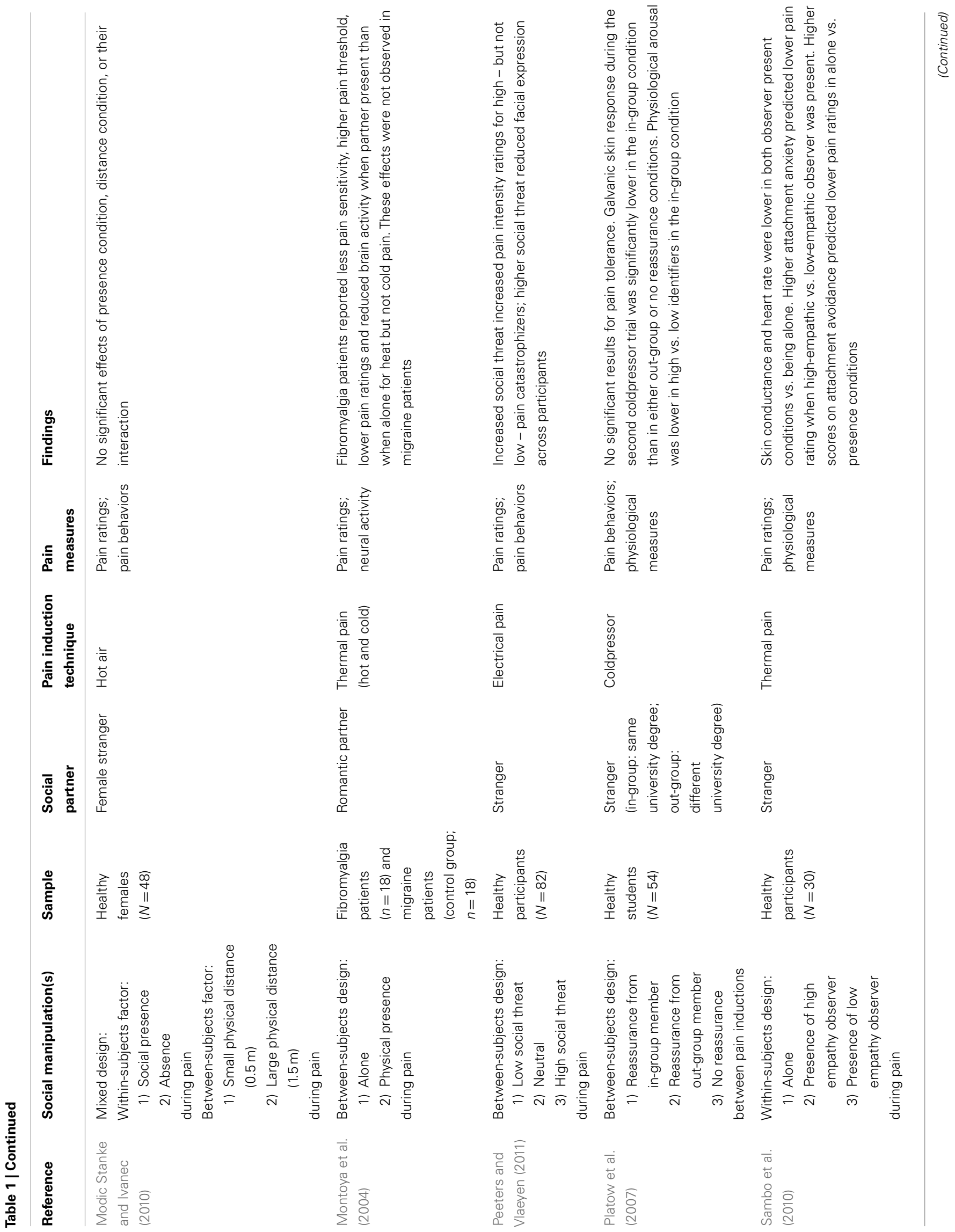




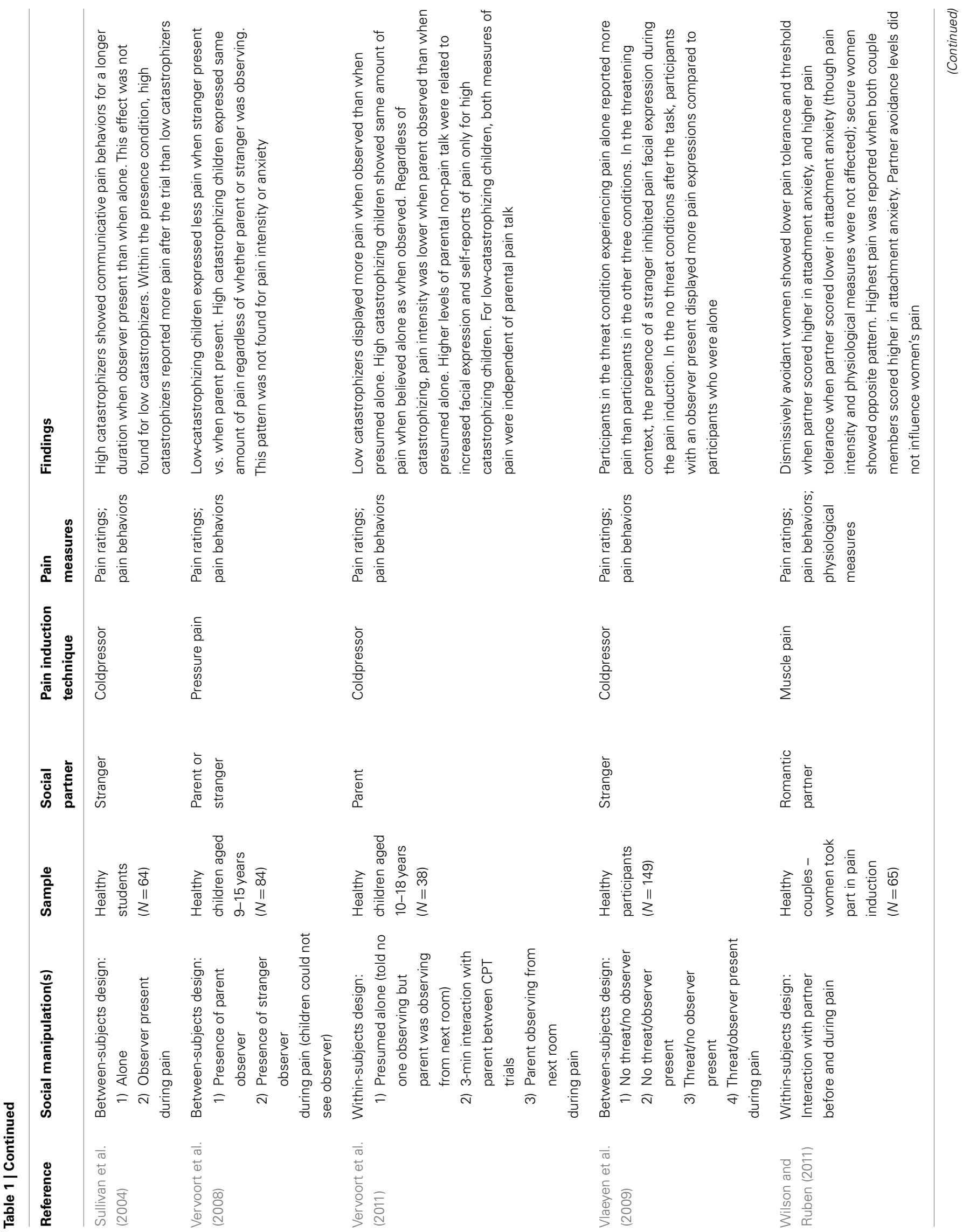




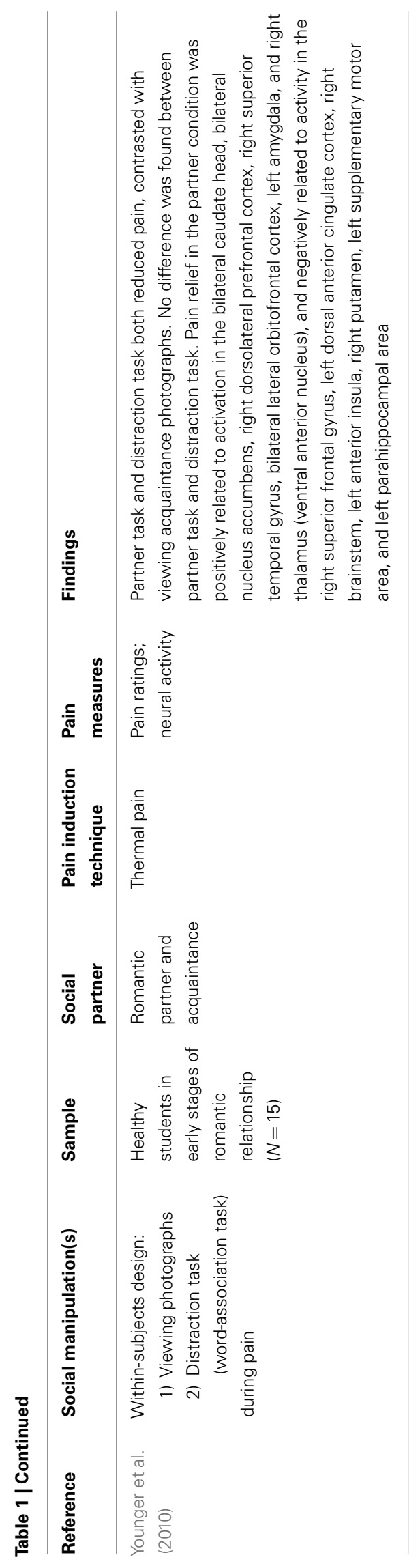

Moreover, the studies manipulated a variety of interpersonal factors including verbal interactions (e.g., Chambers et al., 2002; Jackson et al., 2005), non-verbal interactions (e.g., hand-holding; Master et al., 2009), mere physical presence of the social partner (Brown et al., 2003; Vervoort et al., 2008), priming by photographs of partners (e.g., Eisenberger et al., 2011) and manipulations of participants' perception of the social partner (e.g., Sambo et al., 2010; Peeters and Vlaeyen, 2011). Also, studies differed in terms of the characteristics of their sample, for instance participant and partner gender, and personality traits (e.g., pain catastrophizing; Sullivan et al., 2004; or attachment style; Sambo et al., 2010; Wilson and Ruben, 2011). To review such heterogeneous data, and motivated by interactionist accounts of social cognition (e.g., Bartz et al., 2011), we drew a distinction between studies in which social partners were perceived by the participants to be active or to possess possibility for action (see The Social Partner's Possibility for Action), and studies in which social partners did not appear to have possibility for action (see No Perceived Possibility for Action). At the most apparent level, this involved distinguishing between on-line and off-line, or primed social contexts. While the former included interactions in which the social partner was physically present, the latter used social stimuli (e.g., photographs) rather than interactions with a live social partner; thus, the two contexts differed in possibility for action by the social partner.

Secondly, independent of this "possibility for action" subdivision, we distinguished between different types of relationships, according to whether the social partner was a stranger (e.g., Jackson et al., 2005), a parent (e.g., Vervoort et al., 2011), a friend (e.g., McClelland and McCubbin, 2008), or the romantic partner (e.g., Master et al., 2009) of the person in pain (see Relationship Between the Social Partner and the Person in Pain). We further particularly examined studies according to the interaction history, contrasting rich interaction histories (parent, partner, and friend) with one-off interactions with strangers. Previous experiences with the social partner were considered to be important not only from an attachment perspective (see below) but also in terms of predictability of the other's mental state, which we address in the discussion.

It is important to emphasize that while we organized the data around the categories of "possibility for action" and "type of relationship" separately, most aspects of interpersonal interactions are likely to interact in various dynamic ways to create the overall social context of pain. We point the reader to related sections as appropriate throughout the review and present an overall theoretical conceptualization (based on a free energy framework) of such dynamic patterns in the discussion.

\section{THE SOCIAL PARTNER'S POSSIBILITY FOR ACTION}

Twenty-two studies manipulated aspects of interpersonal interactions in which the social partner was physically present and was perceived to have the possibility to act toward the person in pain. In nine of these studies, the social manipulation involved the opportunity of engaging in verbal communication with a social partner, while the remaining 13 studies manipulated social presence without verbal communication. 


\section{Possibility for action and verbal interaction}

In studies manipulating verbal interactions, the social partner was generally designed to act in a socially supportive role toward the person in pain. Social support is a complex construct, broadly conceptualized as "resources and interactions with others that help people cope with problems" (Masters et al., 2007, p. 11) and thus includes clear possibilities for action. Six studies (Chambers et al., 2002; Brown et al., 2003; Jackson et al., 2005, studies 1 and 2; Jackson et al., 2009; Wilson and Ruben, 2011) included conditions in which the content of the interaction was unstructured (i.e., not pre-determined by the experimenters). In Brown et al.'s (2003) study, this unstructured condition took the form of an "interaction" condition, in which the social partner was not instructed to behave in any particular way and the participant could shape the interaction. Three further conditions involved active support (explicitly supportive comments), passive support (presence without verbal interaction), and experiencing pain alone. Regardless of whether the social partner was a friend or a stranger, participants reported more pain in the unstructured interaction condition and when experiencing pain alone than they did in the active and passive support conditions (Brown et al., 2003). Though the authors did not record the verbal content of the unstructured interaction condition, they suggested that the interaction could have included negative comments, which may have counteracted any benefits of social support. Similarly, Jackson and colleagues found in a first study that participants who spoke to an empathic experimenter ("transaction opportunity" condition) showed reduced pain tolerance and increased pain intensity compared to participants who did not speak to the experimenter (Jackson et al., 2005, study 1). This was mirrored in their second study (Jackson et al., 2005, study 2), in which female participants displayed the lowest pain tolerance in the transaction opportunity condition, compared to structured conditions, such as distraction and encouragement conditions. Lastly, Chambers and colleagues trained mothers to respond to their children's pain in either pain-promoting ways (which included reassurance, empathy, mild criticism, and giving control to the child) or pain-reducing ways (which included distraction with an alternative task, humor, and "encouragement to use coping strategies"), or mother and child interacted as normal in an unstructured way. Girls reported highest pain intensity in the pain-promoting group, followed by the unstructured interaction, and then the pain-reducing condition (Chambers et al., 2002). These effects were not present in boys, in accordance with other findings (Jackson et al., 2005, study 2; Jackson, 2007). As the pain-promoting condition included different social attitudes (e.g., empathy and mild criticism were included in the same interaction condition), it may have been more mixed than other structured conditions, in accordance with Brown et al.'s explanation regarding their unstructured condition. It thus seems that unstructured or mixed valence verbal interactions with an observer can worsen the experience of pain.

In addition, Wilson and Ruben (2011) discovered that adult attachment style moderated the relationship between unstructured verbal interactions and pain. Attachment styles derive from attachment theory (Bowlby, 1977) and are individual differences in interpersonal relating formed in infancy over repeated interactions with a primary caregiver. These styles are relatively stable across the lifespan (Main et al., 1985; Waters et al., 2000). In adulthood, attachment styles are generally classified as secure or insecure; the latter commonly being subdivided into anxious and avoidant styles (though attachment styles are also viewed dimensionally, e.g., Fraley et al., 2000). In brief, securely attached adults are typically comfortable with closeness and depending on others, while anxious adults are preoccupied with the relationship and fear abandonment, and avoidant individuals are uncomfortable with closeness and lack trust in relationship partners (Hazan and Shaver, 1987). Wilson and Ruben found that in couples in which the woman received noxious stimuli, highest pain was reported when both members of the couple had higher levels of attachment anxiety. Further, avoidant women showed lower pain tolerance when the social partner was more anxiously attached, whereas securely attached women showed higher pain tolerance when the social partner was more anxiously attached (Wilson and Ruben, 2011).

In a related study examining the moderating role of attachment style, Sambo et al. (2010) manipulated the "perceived empathy" of a present social partner. While empathy predicts social support provision (Devoldre et al., 2010) and plays an important role in health care settings (Blasi et al., 2001; Tait, 2008), its effects on pain remain understudied in experimental contexts, though some studies have included empathy as one element of a multifaceted manipulation (e.g., Chambers et al., 2002; see above). "Perceived empathy" describes participants' knowledge of the social partner's level of understanding of their pain (Sambo et al., 2010). In a within-subject design, Sambo et al. informed participants prior to the administration of noxious stimuli that each of the experimenters present during each of two identical blocks of noxious stimulation had either expressed high or low empathy for them during initial thresholding (determining a participant's pain threshold). In a third condition, participants experienced pain alone. Although participant and social partner did not communicate during pain induction, the empathy manipulation was verbal, and is thus reviewed here. The perceived empathy manipulation interacted with the participants' adult attachment style to affect pain, in that higher attachment anxiety predicted less pain in the high empathy compared to the low empathy condition. However, it should be noted that the manipulated facet of empathy was thus quite "cognitive" in nature and it is unclear how it may compare to natural social contexts in which empathy is not only verbally but also behaviorally communicated.

Moreover, four experiments manipulated structured interpersonal interactions, that is, instances of interpersonal interactions with set verbal elements (e.g., certain sentences the interaction partner always used) or a clear theme (e.g., supportive comments). Conditions such as distraction, reinterpretation, and encouragement (Jackson et al., 2005) and active support (Brown et al., 2003) all led to increased pain tolerance relative to transaction opportunity conditions (see above). Although Chambers et al. (2002) included several verbal elements, the nature of their pain-reducing condition was supportive overall, and indeed it was found to reduce pain relative to other conditions in girls. While these interactions all exerted pain-reducing effects, it seems likely that the mediating mechanisms may have differed, since the interactions 
compared were quite varied, e.g., distraction vs. reinterpreting pain-related cognitions (Jackson et al., 2005) (see Discussion).

In summary, unstructured verbal interactions were found to increase pain and were influenced by adult attachment style. The effects of structured verbal interactions depended on the content and valence of the interaction. While interactions with a clear theme positive valence, e.g., encouragement, reinterpretation, and active emotional support, reduced certain pain measures, interactions with mixed verbal content, and valence were pain-promoting, even when they included one of the above "positive" factors such as reassurance. Notably, the effects of verbal interactions on pain were mainly found in women but not men.

\section{Possibility for action and non-verbal social presence}

Thirteen studies manipulated social presence during pain without verbal communication. Manipulations ranged from the mere presence of a supportive other (e.g., Flor et al., 1995) to varying the threat of the social partner (e.g., Peeters and Vlaeyen, 2011) and interpersonal distance (Modic Stanke and Ivanec, 2010), to conditions using hand-holding (Master et al., 2009). While some manipulations did not involve any actual interaction between person in pain and observer, possibility for action by the social partner was salient as the social partner was physically present. Further, though several studies placed the social partner in an adjacent observation room (Kleck et al., 1976, studies 1 and 2; Vervoort et al., 2008, 2011), we considered that participants perceived their partners as capable of action because participants were aware that their social partner was observing them during pain induction (as opposed to encounters prior to pain induction, see Social Partner without Perceived Possibility for Action during Pain). In addition, the results of these studies were comparable with the other studies in which the social partner was present in the same room, in that social manipulations influenced participants' facial expressions, which portray a communicative intent (e.g., Williams, 2002).

Kleck et al. (1976, studies 1 and 2) discovered that participants showed reduced facial expressions and reported less pain when they were observed than when they were alone; this was also found for physiological measures (Sambo et al., 2010), pain ratings in participants who received passive support from a friend or a stranger (Brown et al., 2003) or reported having low levels of social support in general (McClelland and McCubbin, 2008); for participants with high levels of self-reported everyday social support, pain ratings were higher in the presence of a friend than alone (McClelland and McCubbin, 2008). In addition, participants with a solicitous spouse showed a reduced pain threshold and tolerance in the presence of the spouse vs. alone (Flor et al., 1995). These latter findings fit within models of chronic pain positing that high social support may be positively reinforcing and ultimately lead to increased and prolonged pain (see Insights from Clinical Studies). Furthermore, in the aforementioned study on the role of perceived empathy on pain measures (Sambo et al., 2010), avoidant attachment was the only factor that moderated the relationship between social presence and pain report, such that higher attachment avoidance predicted more pain in the presence vs. alone condition, possibly because avoidant individuals prefer to cope on their own.
In addition to the above moderating factors, several studies which tested the communal coping model of pain catastrophizing (see Insights from Clinical Studies) reported that pain catastrophizing moderated the effects of presence on pain. Unfortunately, the direction of such effects varied between studies: only high pain catastrophizers (Sullivan et al., 2004) vs. only low pain catastrophizers (Vervoort et al., 2011) were found to exhibit facial expressions for a longer time period in the presence of a social partner than when alone. In addition, Vervoort et al. (2008) demonstrated that low-catastrophizing children displayed less pain when a stranger rather than their parent was present. It is possible that a stranger may be perceived as more threatening than a parent, leading to the inhibition of facial expressions. Indeed, three studies varied perceived threat during the social situation. They found that the presence of a stranger during a threatening situation (Jackson et al., 2009; Vlaeyen et al., 2009), as well as the threat appraisal of the strangers themselves (Peeters and Vlaeyen, 2011) led to attenuated facial expressions of pain (Vlaeyen et al., 2009; Peeters and Vlaeyen, 2011) and reduced pain tolerance (Jackson et al., 2009), i.e., increased pain sensations.

Lastly, we considered pain-modulatory effects of interpersonal distance between social partner/s and the person in pain. Interpersonal distance can modulate intimacy between people (Sussman and Rosenfeld, 1982), and violations of personal space can increase aversion of the social partner (Sussman and Rosenfeld, 1978). Conversely, a sense of safety and intimacy provided by a trusted other might be diminished if they are physically distant and unable to help. However, only one study directly investigated the effects of physical distance on pain (Modic Stanke and Ivanec, 2010). In this study, the social partner was positioned either 0.5 or $1.5 \mathrm{~m}$ from the person receiving pain. No effects of distance on pain were found. However, both social partner and participants in pain were female. Women have been found to maintain smaller interpersonal distances (i.e., choose to sit closer together) and do not see close distances as violations of space compared to men (Sussman and Rosenfeld, 1978, 1982; Holland et al., 2004). Therefore, at present, we cannot draw any conclusions on the effects of interpersonal distance on pain.

Overall, social presence differentially impacts pain according to individual differences of the person in pain or of the social partner. Participants reporting higher levels of everyday social support and higher attachment avoidance, as well as participants with a solicitous spouse, had worse pain outcomes when a social partner was present than when they were alone, while participants with low levels of everyday social support showed the opposite effects. Unfortunately, the direction of the moderating effect of pain catastrophizing remains unclear, while environmental threat seems to exacerbate pain.

Only one study coupled social presence with a direct action toward the participant (Master et al., 2009). In this study, handholding was employed as a form of social support. In different conditions in a within-subject design, female participants held the hand of their partner, or the hand of a stranger, or held an object. Reductions in pain unpleasantness were found when holding the hand of the romantic partner during pain compared to when holding a stranger's hand or holding an object (these differences were not due to distraction, as participants' reaction times to random 
computer-generated beeps did not differ across conditions). This finding is consistent with a study showing that unpleasantness ratings and neural responses to the threat of electric shocks were reduced when participants held their spouse's hand as opposed to a stranger's hand or no hand at all (Coan et al., 2006). Although the latter study assessed "threat of pain" and not pain per se (and hence was not included in Table 1), taken together both these studies suggest that holding the hand of the romantic partner can reduce pain-related unpleasantness. However, a few methodological issues deserve mention. Hand squeezing was not measured in either study and holding a stranger's hand may be a somewhat unusual and potential socially uncomfortable condition. Further, a condition without touch (i.e., holding no hand at all) arguably differs from the other two in terms of multisensory integration.

In conclusion, verbal and non-verbal interpersonal interactions with perceived possibility for action were found to be pain-reducing only when specific verbal behaviors with positive intention, such as supportive comments, reinterpretation, and distraction, or non-verbal interactions with a clear positive social meaning (e.g., holding one's partner's hand) were manipulated and participants had low levels of self-reported social support and attachment avoidance. By contrast, more unstructured, emotionally negative, varied, or vague social manipulations led to increases in pain, either directly (e.g., presence conditions with unstructured verbal content) or in interaction with variables linked to the perception of threat and anxiety, such as catastrophizing and threat manipulations.

\section{NO PERCEIVED POSSIBILITY FOR ACTION}

Studies with no possibility for action were defined by the absence of a social partner during pain induction. Here, social manipulations were classified according to two sub-categories. In a first set of three studies, interpersonal variables were manipulated by priming. Second, two studies involved a partner who was present before pain induction but not during pain induction.

\section{Primed interpersonal contexts}

Three studies presented participants with photographs of their partner and either a stranger and an object (Master et al., 2009; Eisenberger et al., 2011) or an acquaintance (Younger et al., 2010). All studies discovered that viewing pictures of the partner reduced pain relative to viewing stranger/acquaintance and object pictures. While such effects might be explained by distraction or familiarity of the partner, two studies assessed distraction (see Possibility for Action and Non-Verbal Social Presence for details on Master et al., 2009) and Younger et al. (2010) included a word-association task condition. They also controlled for familiarity by comparing viewing pictures of a partner with viewing pictures of an equally attractive and familiar acquaintance. However, the other two studies cannot rule out possible familiarity effects (Master et al., 2009; Eisenberger et al., 2011) and Eisenberger et al. (2011) cannot exclude possible distraction effects.

Two of the three studies (Younger et al., 2010; Eisenberger et al., 2011) also employed functional neuroimaging techniques and reported neural activations during the different social conditions. Most notably, pain attenuation in the partner picture condition was positively linked to activation in areas associated with safety-signaling (the ventromedial prefrontal cortex; Eisenberger et al., 2011), and reward processing (e.g., the caudate head and nucleus accumbens; Younger et al., 2010). Based on this finding, two neurocognitive mechanisms potentially mediating the beneficial effects of viewing partner pictures were put forward. First, ventromedial prefrontal cortex activation was not only found during partner picture viewing but was further negatively correlated with both pain ratings and pain-related neural activity. Hence, it was claimed that viewing pictures of an attachment figure (i.e., the partner) signaled safety in the face of threat (pain), which contributed to pain attenuation (Eisenberger et al., 2011). The second proposed mediating mechanism concerned reward-related neural activation, which has previously been positively associated with intense love (Aron et al., 2005). In Younger et al.'s (2010) study, viewing pictures of the partner and a distraction task both reduced pain, but only the partner condition was associated with activation in the bilateral caudate head, bilateral nucleus accumbens, amygdala, hypothalamus, pregenual ACC, and medial orbitofrontal cortex, which play a role in the processing of rewards (Aron et al., 2005). Reward processing has in turn been linked to pain attenuation (e.g., Wood, 2006) and placebo analgesia (e.g., Scott et al., 2007). Such mechanisms may explain why pain was not attenuated when viewing pictures of strangers or acquaintances, who are not involved in a pre-existing loving attachment relationship with the person in pain.

Taken together, showing participants photographs of their romantic partner may reduce pain by priming attachment or love themes and related brain networks. The role of distraction and familiarity in some of these studies remains to be established.

\section{Social partner without perceived possibility for action during pain}

Two studies employed a social partner who interacted with the participant before but was absent during pain induction (Platow et al., 2007; Borsook and MacDonald, 2010). The first investigated whether the effects of reassuring comments depended on in-group or out-group status of the social partner, while Borsook and MacDonald studied socially induced hypoalgesia (reduced pain in the face of a stimulus that is normally perceived as painful; IASP, 1994) by negative vs. positive interpersonal interactions. Contrary to studies with perceived possibility for action (see The Social Partner's Possibility for Action), both found that positive encounters before pain induction did not affect pain ratings or pain tolerance during pain induction, highlighting the importance of possibility for action. However, reassurance from an in-group member did selectively reduce physiological arousal ( $\mathrm{Pla}-$ tow et al., 2007). Furthermore, negative interpersonal interactions preceding pain induction were associated with reductions in pain ratings, attributed to social harm induced hypoalgesia (Borsook and MacDonald, 2010).

In sum, social manipulations characterized by the absence of a social partner during pain seemed to reduce pain only when they were interpersonally relevant, e.g., when there existed a close (attachment) bond between the social partner and the person in pain, or the social partner was an in-group member of the person in pain. 
RELATIONSHIP BETWEEN THE SOCIAL PARTNER AND THE PERSON IN PAIN

The reviewed studies differed in terms of the relationship between participant and social partner. Most commonly, the social partner was a stranger (18 studies), the partner (six studies), a parent (three studies), or a friend/acquaintance (four studies) of the participant ${ }^{1}$. In one study, the nature of the social partner was not specifically defined (had to be at least an acquaintance but could also be the partner, Jackson et al., 2009; counted as acquaintance above), and thus it was not possible to evaluate relationship effects in this study.

Perhaps due to partner manipulation studies coming from similar research backgrounds and being designed to be positive (e.g., supportive), these studies generally found that the romantic partner reduced pain, although this effect was moderated by adult attachment style (Wilson and Ruben, 2011) and spouse solicitousness (Flor et al., 1995). Also, social manipulations were more homogeneous when the social partner was the romantic partner, presumably because they were constrained by the couple's relationship history. For example, a very empathic partner being assigned to a high social threat condition in which they supposedly chose to administer a high number of pain trials to their partner (as in Peeters and Vlaeyen, 2011) might not seem believable to the person in pain. Likewise, certain social manipulations such as hand-holding may be inherently more suitable for pre-existing relationships.

The effects of interacting with strangers were most diverse, possibly due to the range of social manipulations, social meanings, and varying degrees of knowledge of the stranger's mental state. For example, some studies gave participants no information about the stranger's mental state (e.g., Sullivan et al., 2004, stated that the stranger was present only to monitor the water temperature of the coldpressor), some presented personally irrelevant information about the stranger's mental state (e.g., Vervoort et al., 2008, informed participants that the stranger present was a student observing the experimental session to learn about the pain procedure) and others gave participants personally relevant information regarding the stranger's mental state, for example how much empathy the stranger had for the participant (Sambo et al., 2010). When interactions with different types of social partners were compared within the same experiment, with social manipulations remaining constant, partners were found to reduce pain more than strangers or acquaintances (Master et al., 2009; Younger et al., 2010; Eisenberger et al., 2011), but most of these studies did not control for familiarity effects. Parents did not differ from strangers in their impact on pain intensity but increased facial expressions of pain relative to strangers in low-catastrophizing children (Vervoort et al., 2008). Furthermore, interacting with a friend was found not to differ from interacting with a stranger in affecting pain (Brown et al., 2003).

Overall, it appears that the type of relationship between participant and social partner may moderate how interpersonal factors affect pain. In general, pain seems to be attenuated when the

${ }^{1}$ Note that the total number exceeds 26 because several studies included more than one type of social partner. participant is receptive to support (e.g., anxiously attached) and knows the partner is positively oriented toward them (but not highly solicitous), either due to a pre-existing relationship (e.g., between romantic partners), or experimental manipulation (e.g., empathy levels of previously unknown confederates are communicated to the participant). Comparing different types of relationships within the same experimental set-up to tease apart the relative influence of social manipulation and interpersonal relationship on participants' pain remains an ongoing issue for future research.

\section{DISCUSSION}

This paper aimed to provide a systematic review of experimental studies investigating how interpersonal factors influence pain perception and communication. We examined 26 studies with a focus on the type of social manipulations, individual difference characteristics, and the person in pain's relationship with the social partner. Overall, we found that unambiguously positive verbal and non-verbal interactions or positive interpersonally relevant primed interactions reduced pain, while negative, mixed valence, or ambiguous interactions led to increases in pain-related measures. These findings were moderated by individual differences of the person in pain and the social partner, such as adult attachment style.

We propose that the key findings from this review can be integrated into a free energy framework (see Introduction). Specifically, we argue that the perception of interpersonal interactions in the context of pain can affect perceptual and active inferential processes about pain by influencing the certainty or precision of an individual's predictions about an impending stimulus vs. the certainty or precision of related prediction errors. Top-down predictions are not just about the content of lower level representations but also predict their context, defined in mathematical terminology as the precision of a probability distribution (inverse variance or uncertainty; Friston, 2009). Thus, precision refers to confidence in predictions; for example, the allocation of attention toward appropriately salient events can optimize the confidence in prediction errors and influence the relative weighting or importance of prediction errors (Feldman and Friston, 2010). This kind of top-down prediction in sensory cortices is thought to be mediated by cholinergic neuromodulatory mechanisms that optimize the attentional gain of populations encoding prediction errors (Feldman and Friston, 2010), as well as by dopamine in frontostriatal circuits (Fiorillo et al., 2003). In interoception, precision may relate to attention to signals from the body or interoceptive sensitivity (Farb et al., 2013; Fotopoulou, 2013) and may be modulated by several contextual factors. Therefore, interpersonal interactions may affect pain by changing the precision of top-down predictions about pain. This notion of social modulation as precision modulation can be seen as similar to previous psychological accounts (e.g., Van Kleef, 2009) which put forward that social interactions inform inferential processing of the environment (e.g., in developmental research, a mother's facial expressions may influence processing regarding the safety vs. threat of a visual cliff environment). Integrating such notions within a predictive coding model places them in a wider and neurobiologically plausible framework. 


\section{INTERPERSONAL INTERACTIONS AS PRECISION MODULATION}

Based on the reviewed studies, we put forward that interpersonal interactions may affect the precision of an individual's predictions and thus pain in at least two ways: (a) by signaling the safety or threat of noxious stimuli (interoceptive salience) or (b) by signaling the safety or threat of the environment in which stimuli occur (environmental salience).

\section{Precision of predictions about an impending stimulus itself}

The present review revealed that certain interpersonal interactions may directly signal information about the safety or threat of an impending stimulus. Supportive interactions focusing on the painful sensations themselves increased pain tolerance, while interactions in which the threat of noxious stimuli was emphasized reduced pain tolerance. Specifically, a social partner helping participants to re-interpret uncomfortable sensations as neutral or positive sensations increased pain tolerance scores (Jackson et al., 2005) and decreased pain intensity ratings (Jackson, 2007). The social partner signaling that the noxious stimulus was safe thus shaped participants' prediction that the stimulus was safe, which in turn may have reduced the salience of the stimulus and thus pain. In contrast, both social partner and participant reading threatening information about the noxious stimulus increased the number of pain words in their conversation during pain and decreased pain tolerance relative to other conditions (Jackson et al., 2009), possibly because the social partner amplified the threat and hence improved precision and salience.

Moreover, the present results showed that interpersonal interactions may influence the salience of noxious stimuli by modulating the participant's attention toward or away from the noxious stimulus. Verbal interactions directing the participant's attention away from the noxious stimulus (e.g., Chambers et al., 2002; Jackson, 2007), non-social distraction conditions (Younger et al., 2010), and conditions in which distraction could have been a factor (Eisenberger et al., 2011) generally found that diverting attention away from the noxious stimulus led to increased pain tolerance and reduced pain ratings. Therefore, distraction might attenuate pain by reducing the precision of top-down predictions, which in turn may have decreased the salience of the noxious stimulus and hence pain.

\section{Precision of predictions about the environment}

The reviewed studies highlighted that in addition to information about the impending stimulus itself, interpersonal interactions may signal safety or threat of the environment in which the stimulus will occur, and thus modulate pain. In particular, interactions with a clear content regarding the provision of safety or support, or the partner having the possibility to act to protect the person in pain might increase the perception of environmental safety and thus indirectly decrease the perceived threat of noxious stimuli. Indeed, explicitly supportive verbal (e.g., Brown et al., 2003) and embodied (hand-holding; Master et al., 2009) interactions reduced pain, while pain-promoting and threatening conditions increased pain (Chambers et al., 2002; Jackson et al., 2009). By contrast, interactions without a clearly supportive content or possibility of supportive action may not increase the safety value of the environment. Indeed, the present review revealed that unstructured or mixed verbal interactions led to more pain relative to structured verbal interactions with supportive content.

\section{THE PERCEPTION OF INTERPERSONAL INTERACTIONS PER SE}

In addition to the influence of interpersonal interactions on pain, the perception of interpersonal interactions themselves may depend on (a) an individual's prior beliefs about interpersonal relating and the meaning of related interactions, and (b) the certainty or precision with which an interpersonal interaction may predict environmental threat or safety.

\section{Prior beliefs about interpersonal relating}

When examining the effects of interpersonal interactions on pain, it is vital to take into account "historicity"; that is, the backdrop of individual social development against which current social exchanges are placed (Schilbach et al., in press). In a free energy framework, such consideration entails examining not only how predictions are updated "on-line," but also across the life span in slower time scales (Friston, 2009). In the reviewed studies (as well as in clinical studies on pain, see Insights from Clinical Studies), several individual characteristics were found to play a role in the perception of interpersonal interactions and how they influence pain. While the role of factors such as catastrophizing and gender remains unclear, the application of attachment theory in pain research has generated some convincing results. Attachment theory posits that from early in life, attachment figures can serve as a "secure base" from which the infant explores the world (Bowlby, 1977). If a secure attachment bond is formed over repeated instances of responsive caregiving, the "secure base" signals safety to the infant, while insecure bonds lead to more ambivalent or even threatening signals from others. These bonds lead to the formation of attachment styles, which remain relatively stable into adulthood (see also section Possibility for Action and Verbal Interaction). In the clinical pain literature, insecure attachment styles have been proposed as crucial vulnerability factors for developing chronic pain (Meredith et al., 2008).

In the reviewed experimental studies, differences in attachment style influenced the effects of interpersonal variables on pain. Sambo et al. (2010) found that participants characterized by higher attachment anxiety, i.e., a fear of abandonment and need for reassurance from others (Mikulincer et al., 2009), reported less pain when social partners showed high compared to low empathy. Hence, when a partner was ostensibly positively oriented toward the participant, and the participant's attachment style was characterized by seeking for signs of reassurance, the social partner signaled safety to the participant, which in turn may have led to the reduction in pain. In contrast, pain was increased when both members of a couple were highly anxious relative to other attachment style constellations (Wilson and Ruben, 2011), possibly because the partner was not able to signal the desired reassurance. Similarly, avoidant women showed lower tolerance when their partner was highly anxious and higher tolerance when their partner was low anxious, reflecting the detrimental effects of environmental anxiety cues on pain. More generally, avoidant individuals, who generally have low trust in others, reported more pain when with others than when alone (Sambo et al., 2010). Overall, the findings 
highlight the importance of attachment priors in affecting the perception of the social partner.

\section{Precision of the salience of the social partner}

In addition to prior beliefs about interpersonal relating, we found that the specificity or salience (precision, mathematically, see above) by which an interpersonal interaction may predict environmental threat or safety might influence how interpersonal interactions are perceived and ultimately how they affect pain. Relevant factors are (1) the transparency of the social partner's intentions and thoughts, (2) the social partner's possibility for action, and (3) the familiarity or the degree of social bonding with the social partner.

Firstly, knowledge of the social partner's mental state might determine the salience of a social interaction. Information provided in the experiment (e.g., the social partner's empathy toward the participant) and prior knowledge about the social partner's mental state and intentions may increase precision, while lack of knowledge of the social partner's mental state may have the opposite effects. Thus, "pure" presence conditions yielded mixed results (see Possibility for Action and Non-Verbal Social Presence), possibly due to lack of information about the intentions, and thoughts of the social partner. Interestingly, unstructured and mixed interactions (which mostly occurred with strangers) were found to increase pain (see Possibility for Action and Verbal Interaction), indicating that uncertain interpersonal interactions do not weaken the impact on pain but rather may even signal increased environmental threat.

Secondly, a social partner's possibility for action may influence the salience of interpersonal interactions. Specifically, the reviewed studies revealed that interpersonal interactions without possibility for action during pain did not affect pain as much as interactions with possibility for action (see Social Partner Without Perceived Possibility for Action During Pain). Exceptions included interactions that were also interpersonally relevant, in which case other mechanisms may have enhanced salience. From the free energy perspective, these findings can be understood as active inference "by proxy." Normally, action minimizes prediction error by changing sensory input (Friston, 2009). In the case of pain in the presence of others who possess possibility for action, social partners may represent an auxiliary action system; they are able to act to change the sensory input for the person in pain (e.g., by pulling a person's hand away from a noxious source). Within an experimental context, the social partner cannot usually change a participant's sensory input. However, they can possess the possibility to do so, e.g., by being present in the experimental setting. Therefore, the higher the perceived possibility for action, the higher the salience of the interaction in terms of influencing safety and threat. Unfortunately, to our knowledge, no study has specifically examined the effects of partners' actual actions on noxious stimuli and therefore this facet of the interpersonal modulation of pain requires further experimental exploration.

Thirdly, interacting with a familiar social partner might also enhance the salience of the social interaction. Close bonding and positive relationship histories (e.g., secure attachment relationships) with established trust may lead to precise predictions of environmental safety in interpersonal interactions with the romantic partner (e.g., Eisenberger et al., 2011). Indeed, our review brought out that positive interactions with romantic partners generally reduced pain measures, except when partners were overly solicitous or insecurely attached (Flor et al., 1995; Wilson and Ruben, 2011). These findings extended to paradigms where the partner was not physically present, but related cognitions and feelings were primed in the individual in pain (e.g., Younger et al., 2010). On the contrary, interactions with strangers yielded mixed results (Jackson et al., 2005; Vlaeyen et al., 2009). Moreover, one study observed that greater relationship quality and bonding between partners was associated with greater pain reduction when photographs of the partner were shown during pain (Eisenberger et al., 2011).

\section{OVERVIEW OF EFFECTS AND THE OVERALL FRAMEWORK}

In summary, we found that clear and structured experimental interactions may lead to reductions in pain measures when they signal safety of the noxious stimulus or the environment in which it occurs or they are designed to direct attention away from the noxious stimulus. These effects are particularly apparent when the interpersonal interaction itself is salient. However, in most cases, the beneficial effects of support will be moderated by characteristics of the person in pain, such as their attachment style and level of pain catastrophizing. Although more data is needed and some studies found contrary effects, the general trend thus far is that insecure attachment and catastrophizing coping strategies worsen the pain experience, particularly during interpersonal interactions that may be ambiguous.

We have put forward a free energy framework for integrating these findings in a unified, biologically plausible theoretical framework. Our key proposal is that the perception of salient interpersonal interactions may enhance the precision of predictive signals regarding the salience of a noxious stimulus in a given environment, thus ultimately affecting the perceptual and active inferential processes that lead to pain perception and related motivated actions. Specifically, interpersonal exchanges affect precision or salience by socially signaling the safety or threat of the impending stimulus itself or the environment in which the stimulus occurs. In turn, at higher levels of the neurocognitive hierarchy and at slower time scales, the perception and interpretation of such interpersonal variables themselves may depend on an individual's prior beliefs about interpersonal relating and the certainty by which an interpersonal interaction may predict environmental threat or safety. A schematic overview is presented in Figure 1.

The precise neurobiological mechanisms by which interpersonal interactions affect pain remain to be determined. Initial findings suggest that their precision-based modulatory role in pain may be related to dopamine-based motivational mechanisms that have been implicated in the rewarding and craving aspects of social bonding in both humans (Younger et al., 2010) and animals and/or their co-activation with opioid and oxytocin mechanisms (see Insights from Animal Studies and Implications for Human Research). Oxytocin is a neuropeptide that has been implicated in social bonding (e.g., Strathearn et al., 2009), attachment (Buchheim et al., 2009), the social modulation of stress (Heinrichs et al., 2003; Chen et al., 2011), and has been shown to increase the 


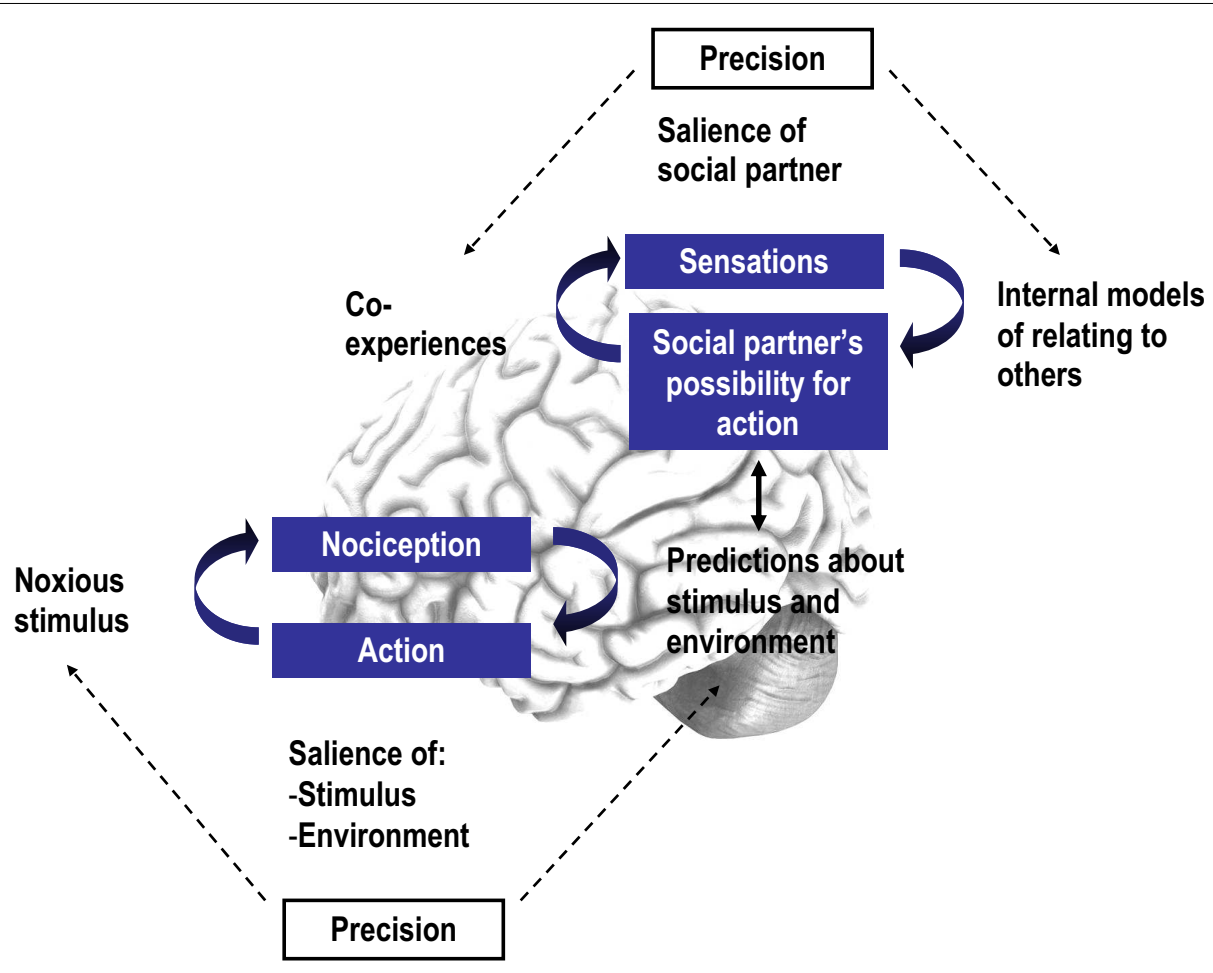

FIGURE 1 | A schematic representation of our free energy framework. The bottom panel depicts how interpersonal interactions may modulate the precision of interoceptive predictions, while the top panel shows the perception of interpersonal interactions per se, and how these influence interoceptive predictions in a top-down manner; the arrow is two-headed to show the interactive nature of the two hierarchical levels. Precision arrows are dashed to demonstrate the dynamic and modulatory, rather than permanent, influence of social context. salience of social stimuli (see Bartz et al., 2011 for a review), perhaps to simultaneously reduce the salience of bodily threat during social experiences that may be valuable for survival (e.g., reproduction, birth etc.). Thus, future studies could explore the role of such neuromodulatory mechanisms and their interactions during pain in social contexts.

\section{LIMITATIONS}

While this paper represents the first systematic review of the social modulation of experimentally induced pain literature, a metaanalysis including direct, quantitative comparisons between studies was not possible due to the great methodological heterogeneity between studies. We were also not able to sufficiently address aspects of study quality, such as sample size, which differed across studies and may have explained some of the variation in findings. A further methodological difference of importance that we could not include was the diversity in study designs, such as sampling issues, ecological validity, pain induction methods, and type of pain measures obtained. For example, interpersonal interactions seem to have differential effects depending on the aspect of pain measured (e.g., pain catastrophizing studies in Possibility for Action and Non-Verbal Social Presence). As most studies included a subset of pain measures, it was not always possible to draw firm conclusions regarding the dependency of the findings on the specific pain measure used. It is further well-recognized that despite the potential of experimental studies to establish causality, the complexity of interpersonal interactions cannot be adequately operationalized in lab-based studies. Similarly, conclusions reached from studies on experimentally induced pain cannot be directly generalized to clinical pain due to the unique environmental and biological characteristics of the latter. Lastly, although we teased apart the different elements of the studies reviewed here to clarify their individual influences, many studies included composite elements within a single manipulation and further research is needed to determine the relative importance and weighting of these factors.

\section{FUTURE PERSPECTIVES AND CHALLENGES}

Although our review focused on interpersonal interactions between a (pain-free) social partner and a person receiving experimentally induced pain, the inclusion of other branches of research, such as social modeling studies and studies manipulating intergroup variables may provide a complementary picture to the present review.

Regarding the design of future studies, more specific manipulations focusing on certain aspects, for example safety or threat or particular facets of social support, could be employed and attempts made to replicate findings with previously used social manipulations. Furthermore, we suggest that varying perceived possibility for action, for example by using both live and primed interactions, and employing different kinds of social partners within the same experimental context (keeping the social manipulation constant) would be interesting avenues to explore. Individual differences, 
such as attachment style and pain catastrophizing, should also be taken into account in future studies.

Expanding on the proposed predictive coding framework, including several instances of interaction and measuring updating of safety vs. threat would be interesting, as well as investigating how lack of precision in interpersonal interactions impacts pain. Nevertheless, focusing on other mechanisms such as reward, attention/distraction by partner, and emotion regulation (e.g., the social baseline model; Coan, 2011) would also be important. Future neuroimaging studies focusing on safety- and threat-related neural activation during corresponding interpersonal interactions (e.g., Coan et al., 2006; see Vrticka and Vuilleumier, 2012, for a review related to attachment style) may add valuable insights into the neural mechanisms of the social modulation of pain. Finally, it

\section{REFERENCES}

Aron, A., Fisher, H., Mashek, D. J., Strong, G., Li, H., and Brown, L. L. (2005). Reward, motivation, and emotion systems associated with early-stage intense romantic love. J. Neurophysiol. 94, 327-337. doi:10. 1152/jn.00838.2004

Auvray, M., Myin, E., and Spence, C. (2010). The sensory-discriminative and affective-motivational aspects of pain. Neurosci. Biobehav. Rev. 34, 214-223.

Barrera, M. (1986). Distinctions between social support concepts, measures, and models. Am. J. Community Psychol. 14, 413-445.

Bartz, J. A., Zaki, J., Bolger, N., and Ochsner, K. N. (2011). Social effects of oxytocin in humans: context and person matter. Trends Cogn. Sci. (Regul. Ed.) 15, 301-309. doi:10. 1016/j.tics.2011.05.002

Baumgärtner, U., Tiede, W., Treede, R.D., and Craig, A. D. (2006). Laserevoked potentials are graded and somatotopically organized anteroposteriorly in the operculoinsular cortex of anesthetized monkeys. J. Neurophysiol. 96, 2802-2808. doi:10.1152/jn.00512.2006

Blasi, Z. D., Harkness, E., Ernst, E., Georgiou, A., and Kleijnen, J. (2001). Influence of context effects on health outcomes: a systematic review. Lancet 357, 757-762.

Block, A. R. (1981). An investigation of the response of the spouse to chronic pain behavior. Psychosom. Med. 43, 415-22.

Boothby, J. L., Thorn, B. E., Overduin, L. Y., and Ward, L. C. (2004). Catastrophizing and perceived partner responses to pain. Pain 109, 500-506. doi:10.1016/j. pain.2004.02.030

Borsook, T. K., and MacDonald, G. (2010). Mildly negative social encounters reduce physical pain sensitivity. Pain 151, 372-377. doi:10. 1016/j.pain.2010.07.022
Bowlby, J. (1977). The making and Aetiology and psychopathology in the light of attachment theory. An expanded version of the Fiftieth Maudsley Lecture, delivered before the Royal College of Psychiatrists, 19 November 1976. Br. J. Psychiatry 130, 201-210. doi:10.1192/bjp.130. 3.201

Brown, E. C., and Brüne, M. (2012). The role of prediction in social neuroscience. Front. Hum. Neurosci. 6, 147. doi:10.3389/fnhum.2012.00147

Brown, J. L., Sheffield, D., Leary, M. R., and Robinson, M. E. (2003). Social support and experimental pain. Psychosom. Med. 65, 276-283. doi:10.1097/01.PSY 0000030388.62434 .46

Buchheim, A., Heinrichs, M., George, C., Pokorny, D., Koops, E., Henningsen, P., et al. (2009). Oxytocin enhances the experience of attachment security. Psychoneuroendocrinology 34, 1417-1422. doi:10. 1016/j.psyneuen.2009.04.002

Buss, A. H., and Portnoy, N. W. (1967). Pain tolerance and group identification. J. Pers. Soc. Psychol. 6, 106-108. doi:10.1037/h0024525

Campbell, A. (2010). Oxytocin and human social behavior. Pers. Soc. Psychol. Rev. 14, 281-295. doi:10. 1177/1088868310363594

Cano, A. (2004). Pain catastrophizing and social support in married individuals with chronic pain: the moderating role of pain duration. Pain 110, 656-664. doi:10.1016/j. pain.2004.05.004

Cano, A., Barterian, J. A., and Heller, J. B. (2008). Empathic and nonempathic interaction in chronic pain couples. Clin. J. Pain 24, doi:10.1097/AJP. 0b013e31816753d8

Cano, A., Johansen, A. B., Leonard, M. T., and DeGroot Hanawalt, J. (2005). What are the marital problems of patients with chronic pain? Curr. breaking of affectional bonds. I. Pain Headache Rep. 9, 96-100.

could prove fruitful to study the central role of the neuropeptide oxytocin in parallel with manipulations of the interpersonal modulation of pain.

\section{ACKNOWLEDGMENTS}

We would like to thank Chiara Sambo for her initial help with this review and the reviewers for their valuable suggestions on how to strengthen this paper. This study was supported by funding from the Volkswagen Foundation "European Platform for Life Sciences, Mind Sciences and Humanities" grant for the "Pain Group Project" (to Aikaterini Fotopoulou and Anne Springer) and the Institute for the Study of Affective Neuroscience (ISAN)/Hope for Depression Research Foundation (HDRF) (to Aikaterini Fotopoulou).

Cano, A., and Williams, A. C. (2010). Social interaction in pain: reinforcing pain behaviors or building intimacy? Pain 149, 9-11.

Cauda, F., Torta, D. M. E., Sacco, K., Geda, E., D’Agata, F., Costa, T., et al. (2012). Shared "core" areas between the pain and other task-related networks. PLoS ONE 7:e41929. doi:10. 1371/journal.pone.0041929

Chambers, C. T., Craig, K. D., and Bennett, S. M. (2002). The impact of maternal behavior on children's pain experiences: an experimental analysis. J. Pediatr. Psychol. 27, 293-301. doi:10.1093/jpepsy/27.3.293

Chen, F. S., Kumsta, R., von Dawans, B., Monakhov, M., Ebstein, R. P., and Heinrichs, M. (2011). Common oxytocin receptor gene (OXTR) polymorphism and social support interact to reduce stress in humans. Proc. Natl. Acad. Sci. U.S.A. 108, 19937-19942. doi:10. 1073/pnas.1113079108

Coan, J. A. (2011). "The social regulation of emotion," in Handbook of Social Neuroscience, eds J. Decety, and J. T. Cacioppo (New York: Oxford University Press), 614-623.

Coan, J. A., Schaefer, H. S., and Davidson, R. J. (2006). Lending a hand: social regulation of the neural response to threat. Psychol. Sci. 17, 1032-1039. doi:10.1111/j. 1467-9280.2006.01832.x

Craig, A. D. (2002). How do you feel? Interoception: the sense of the physiological condition of the body. Nat. Rev. Neurosci. 3, 655-666.

Craig, A. D. (2003). Interoception: the sense of the physiological condition of the body. Curr. Opin. Neurobiol. 13, 500-505.

Craig, K. D. (2009a). The social communication model of pain. Can. Psychol. 50, 22-32.

Craig, A. D. (2009b). How do you feelnow? The anterior insula and human awareness. Nat. Rev. Neurosci. 10, 59-70. doi:10.1038/nrn2555
Critchley, H. D. (2005). Neural mechanisms of autonomic, affective, and cognitive integration. J. Comp. Neurol. 493, 154-166.

Damasio, A., Grabowski, T. J., Bechara, A., Damasio, H., Ponto, L. L., Parvizi, J., et al. (2000). Subcortical and cortical brain activity during the feeling of self-generated emotions. Nat. Neurosci. 3, 1049-1056.

D'Amato, F. R., and Pavone, F. (1993). Endogenous opioids: a proximate reward mechanism for kin selection? Behav. Neural Biol. 60, 79-83.

Dayan, P., and Hinton, G. E. (1996). Varieties of Helmholtz machine. Neural Netw. 9, 1385-1403.

Devoldre, I., Davis, M. H., Verhofstadt, L. L., and Buysse, A. (2010). Empathy and social support provision in couples: social support and the need to study the underlying processes. $J$. Psychol. 144, 259-284. doi:10.1080/ 00223981003648294

Eisenberger, N. I. (2012). Broken hearts and broken bones: a neural perspective on the similarities between social and physical pain. Curr. Dir. Psychol. Sci. 21, 42-47. doi:10.1177/ 0963721411429455

Eisenberger, N. I., Jarcho, J. M., Lieberman, M. D., and Naliboff, B. D. (2006). An experimental study of shared sensitivity to physical pain and social rejection. Pain 126, 132-138.

Eisenberger, N. I., Lieberman, M. D., and Williams, K. D. (2003). Does rejection hurt? An fMRI study of social exclusion. Science 302, 290-292. doi:10.1126/science. 1089134

Eisenberger, N. I., Master, S. L., Inagaki, T. K., Taylor, S. E., Shirinyan, D., Lieberman, M. D., et al. (2011). Attachment figures activate a safety signal-related neural region and reduce pain experience. Proc. Natl. Acad. Sci. U.S.A. 108, 11721-11726. doi:10.1073/pnas.1108239108 
Farb, N. A. S., Segal, Z. V., and Anderson, A. K. (2013). Attentional modulation of primary interoceptive and exteroceptive cortices. Cereb. Cortex 23, 114-126. doi:10.1093/cercor/ bhr385

Feldman, H., and Friston, K. (2010). Attention, uncertainty and freeenergy. Front. Hum. Neurosci. 4:215. doi:10.3389/fnhum.2010.00215

Fiorillo, C. D., Tobler, P. N., and Schultz, W. (2003). Discrete coding of reward probability and uncertainty by dopamine neurons. Science 299, 1898-1902. doi:10.1126/ science. 1077349

Flor, H., Breitenstein, C., Birbaumer, N., and Fürst, M. (1995). A psychophysiological analysis of spouse solicitousness towards pain behaviors, spouse interaction, and pain perception. Behav. Ther. 26, 255-272. doi: 10.1016/S0005-7894(05)80105-4

Flor, H., Kerns, R. D., and Turk, D. C. (1987). The role of spouse reinforcement, perceived pain, and activity levels of chronic pain patients. J. Psychosom. Res. 31, 251-259. doi: 10.1016/0022-3999(87)90082-1

Fotopoulou, A. (2013). Beyond the reward principle: consciousness as precision seeking. Neuropsychoanalysis 15, 29-34.

Fraley, R. C., Waller, N. G., and Brennan, K. A. (2000). An item response theory analysis of self-report measures of adult attachment. J. Pers. Soc. Psychol. 78, 350-365. doi:10.1037/00223514.78.2.350

Friston, K. (2009). The free-energy principle: a rough guide to the brain? Trends Cogn. Sci. (Regul. Ed.) 13, 293-301. doi:10.1016/j.tics.2009.04. 005

Friston, K. J., Shiner, T., FitzGerald, T., Galea, J. M., Adams, R., Brown, H., et al. (2012). Dopamine, affordance and active inference. PLoS Comput. Biol. 8:e1002327. doi:10.1371/ journal.pcbi.1002327

Gil, K. M., Keefe, F. J., Crisson, J. E., and Van Dalfsen, P. J. (1987). Social support and pain behavior. Pain 29, 209-217.

Griffiths, P. E., and Scarantino, A. (2009). "Emotions in the wild: the situated perspective on emotion," in Cambridge Handbook of Situated Cognition, eds P. Robbins, and M. Aydede (Cambridge: Cambridge University Press), 437-453.

Hayes, S. C., and Wolf, M. R. (1984). Cues, consequences and therapeutic talk: effects of social context and coping statements on pain. Behav. Res. Ther. 22, 385-392. doi:10.1016/ 0005-7967(84)90081-0
Hazan, C., and Shaver, P. (1987). Love conceptualized as an attachment process. J. Pers. Soc. Psychol. 52, 511-24. doi:10.1037/0022-3514.52. 3.511

Heinrichs, M., Baumgartner, T., Kirschbaum, C., and Ehlert, U. (2003). Social support and oxytocin interact to suppress cortisol and subjective responses to psychosocial stress. Biol. Psychiatry 54, 1389-1398. doi: 10.1016/S0006-3223(03)00465-7

Hennessy, M. B., Kaiser, S., and Sachser, N. (2009). Social buffering of the stress response: diversity, mechanisms, and functions. Front. Neuroendocrinol. 30, 470-482. doi:10. 1016/j.yfrne.2009.06.001

Hofbauer, R. K., Fiset, P., Plourde, G., Backman, S. B., and Bushnell, M. C. (2004). Dose-dependent effects of propofol on the central processing of thermal pain. Anesthesiology 100, 386-394. doi:10.1097/ 00000542-200402000-00031

Holland, R. W., Roeder, U.-R., van Baaren, R. B., Brandt, A. C., and Hannover, B. (2004). Don't stand so close to me: the effects of selfconstrual on interpersonal closeness. Psychol. Sci. 15, 237-242. doi: 10.1111/j.0956-7976.2004.00658.x

House, J. S., Landis, K. R., and Umberson, D. (1988). Social relationships and health. Science 241, 540-545.

IASP. (1994). "Part III: pain terms, a current list with definitions and notes on usage," in Classification of Chronic Pain, 2nd Edn, eds H. Merskey, and N. Bogduk (Seattle: IASP Press), 209-214.

Jackson, T. (2007). Interpersonal transactions and responses to cold pressor pain among Australian women and men. Sex Roles 56, 55-62. doi: 10.1007/s11199-006-9146-4

Jackson, T., Huang, X., Chen, H., and Phillips, H. (2009). Effects of threatening information on interpersonal responses to pain. Eur. J. Pain 13, 431-438. doi:10.1016/j.ejpain.2008. 05.012

Jackson, T., Iezzi, T., Chen, H., Ebnet, S., and Eglitis, K. (2005). Gender, interpersonal transactions, and the perception of pain: an experimental analysis. J. Pain 6, 228-236. doi: 10.1016/j.jpain.2004.12.004

Jolliffe, C. D., and Nicholas, M. K. (2004). Verbally reinforcing pain reports: an experimental test of the operant model of chronic pain. Pain 107, 167-175.

Keefe, F. J., Lefebvre, J. C., Egert, J. R., Affleck, G., Sullivan, M. J., and Caldwell, D. S. (2000). The relationship of gender to pain, pain behavior, and disability in osteoarthritis patients: the role of catastrophizing. Pain 87, 325-334.

Kerns, R. D., Haythornthwaite, J., Southwick, S., and Giller, E. L. Jr. (1990). The role of marital interaction in chronic pain and depressive symptom severity. J. Psychosom. Res. 34 401-408.

Kikusui, T., Winslow, J. T., and Mori, Y. (2006). Social buffering: relief from stress and anxiety. Philos. Trans. R. Soc. Lond. B Biol. Sci. 361, 2215-2228.

Kirschbaum, C., Klauer, T., Filipp, S. H., and Hellhammer, D. H. (1995). Sex-specific effects of social support on cortisol and subjective responses to acute psychological stress. Psychosom. Med. 57, 23-31.

Kleck, R. E., Vaughan, R. C., CartwrightSmith, J., Burns Vaughan, K., Colby, C. Z., and Lanzetta, J. T. (1976) Effects of being observed on expressive, subjective, and physiological responses to painful stimuli. J. Pers. Soc. Psychol. 34, 1211-1218. doi:10. 1037/0022-3514.34.6.1211

Langford, D. J., Tuttle, A. H., Brown, K. Deschenes, S., Fischer, D. B., Mutso, A., et al. (2010). Social approach to pain in laboratory mice. Soc. Neurosci. 5, 163-170.

Lee, M. C., Mouraux, A., and Iannetti, G. D. (2009). Characterizing the cortical activity through which pain emerges from nociception. J. Neurosci. 29, 7909-7916. doi:10.1523/ JNEUROSCI.0014-09.2009

Legrain, V., Iannetti, G. D., Plaghki, L., and Mouraux, A. (2011). The pain matrix reloaded: a salience detection system for the body. Prog. Neurobiol. 93, 111-124. doi:10.1016/j. pneurobio.2010.10.005

Leonard, M. T., Cano, A., and Johansen, A. B. (2006). Chronic pain in a couples context: a review and integration of theoretical models and empirical evidence. J. Pain 7, 377-390.

Levine, F. M., and De Simone, L. L. (1991). The effects of experimenter gender on pain report in male and female subjects. Pain 44, 69-72.

López-Martínez, A. E., Esteve-Zarazaga, R., and Ramírez-Maestre, C. (2008). Perceived social support and coping responses are independent variables explaining pain adjustment among chronic pain patients. J. Pain 9, 373-379.

Main, M., Kaplan, N., and Cassidy, J. (1985). Security in infancy, childhood, and adulthood: a move to the level of representation. Monogr. Soc. Res. Child Dev. 50, 66-104. doi: $10.2307 / 3333827$
Manimala, M. R., Blount, R. L., and Cohen, L. L. (2000). The effects of parental reassurance versus distraction on child distress and coping during immunizations. Child. Health Care 29, 161-177. doi:10. 1207/S15326888CHC2903\_2

Master, S. L., Eisenberger, N. I., Taylor, S. E., Naliboff, B. D., Shirinyan, D., and Lieberman, M. D. (2009). A picture's worth. Psychol. Sci. 20, 1316-1318. doi:10.1111/j.14679280.2009.02444.x

Masters, K., Stillman, A., and Spielmans, G. (2007). Specificity of social support for back pain patients: do patients care who provides what? J. Behav. Med. 30, 11-20. doi:10.1007/ s10865-006-9078-z

McCall, C., and Singer, T. (2012). The animal and human neuroendocrinology of social cognition, motivation and behavior. Nat. Neurosci. 15, 681-688. doi:10.1038/nn. 3084

McClelland, L., and McCubbin, J. (2008). Social influence and pain response in women and men. J. Behav. Med. 31, 413-420. doi:10. 1007/s10865-008-9163-6

McGrath, P. A. (1983). The biologic basis of pain and analgesia: the role of situational variables in pain control. Anesth. Prog. 30, 137-146.

Medford, N., and Critchley, H. (2010). Conjoint activity of anterior insular and anterior cingulate cortex: awareness and response. Brain Struct. Funct. 214, 535-549. doi:10.1007/ s00429-010-0265-x

Meredith, P., Ownsworth, T., and Strong, J. (2008). A review of the evidence linking adult attachment theory and chronic pain: presenting a conceptual model. Clin. Psychol. Rev. 28, 407-429. doi:10.1016/j.cpr.2007. 07.009

Meredith, P. J., Strong, J., and Feeney, J. A. (2006). The relationship of adult attachment to emotion, catastrophizing, control, threshold and tolerance, in experimentallyinduced pain. Pain 120 , 44-52.

Mesulam, M. (2012). The evolving landscape of human cortical connectivity: facts and inferences. Neuroimage 62, 2182-2189. doi:10.1016/j. neuroimage.2011.12.033

Mikulincer, M., Shaver, P. R., SapirLavid, Y., and Avihou-Kanza, N. (2009). What's inside the minds of securely and insecurely attached people? The secure-base script and its associations with attachmentstyle dimensions. J. Pers. Soc. Psychol. 97, 615-633. doi:10.1037/a0015649 
Modic Stanke, K., and Ivanec, D. (2010). Social context of pain perception: the role of other people's presence and physical distance. Rev. Psychol. 17, 69-74.

Mogil, J. S. (2009). Animal models of pain: progress and challenges. Nat. Rev. Neurosci. 10, 283-294. doi:10. 1038/nrn2606

Montoya, P., Larbig, W., Braun, C., Preissl, H., and Birbaumer, N. (2004). Influence of social support and emotional context on pain processing and magnetic brain responses in fibromyalgia. Arthritis Rheum. 50, 4035-4044. doi:10.1002/ art.20660

Mouraux, A., Diukova, A., Lee, M. C., Wise, R. G., and Iannetti, G. D. A. (2011). multisensory investigation of the functional significance of the "pain matrix". Neuroimage 54, 2237-2249. doi:10.1016/j

Newton-John, T. R. (2002). Solicitousness and chronic pain: a critical review. Pain Rev. 9, 7-27. doi:10. 1191/0968130202pr186ra

Nikolajsen, L., and Jensen, T. S. (2006). "Phantom limb," in Textbook of Pain, 5th Edn, eds S. B. McMahon, and M. Koltzenburg (Edinburgh: Churchill Livingstone), 961-971.

Norman, G. J., Karelina, K., Morris, J. S., Zhang, N., Cochran, M., and Courtney DeVries, A. (2010). Social interaction prevents the development of depressive-like behavior post nerve injury in mice: a potential role for oxytocin. Psychosom. Med. 72, 519-526. doi:10.1097/PSY. 0b013e3181de8678

Panksepp, J. (1998). Affective Neuroscience: The Foundations of Human and Animal Emotions. New York: Oxford University Press.

Panksepp, J. (2006). "On the neuroevolutionary nature of social pain, support, and empathy," in Pain: New Essays on its Nature and the Methodology of its Study, ed. M. Aydede (Cambridge: The MIT Press), 367-387.

Panksepp, J., Nelson, E., and Bekkedal, M. (1997). Brain systems for the mediation of social separationdistress and social-reward evolutionary antecedents and neuropeptide intermediaries. Ann. N. Y. Acad. Sci. 807, 78-100. doi:10.1111/j.17496632.1997.tb51914.x

Payne, B., and Norfleet, M. A. (1986). Chronic pain and the family: a review. Pain 26, 1-22.

Peeters, P. A. M., and Vlaeyen, J. W. S. (2011). Feeling more pain, yet showing less: the influence of social threat on pain. J. Pain 12, 1255-1261. doi: 10.1016/j.jpain.2011.07.007
Penner, L. A., Cline, R. J. W., Albrecht, T. L., Harper, F. W. K., Peterson, A. M., Taub, J. M., et al. (2008). Parents' empathic responses and pain and distress in pediatric patients. Basic Appl. Soc. Psych. 30, 102-13.

Platow, M. J., Voudouris, N. J., Coulson, M., Gilford, N., Jamieson, R., Najdovski, L., et al. (2007). In-group reassurance in a pain setting produces lower levels of physiological arousal: direct support for a self-categorization analysis of social influence. Eur. J. Soc. Psychol. 37, 649-660. doi:10.1002/ejsp.381

Rao, R. P., and Ballard, D. H. (1999). Predictive coding in the visual cortex: a functional interpretation of some extra-classical receptive-field effects. Nat. Neurosci. 2, 79-87.

Romano, J. M., Turner, J. A., Jensen, M. P., Friedman, L. S., Bulcroft, R. A., Hops, H., et al. (1995). Chronic pain patient-spouse behavioral interactions predict patient disability. Pain $63,353-360$.

Sambo, C. F., Howard, M., Kopelman, M., Williams, S., and Fotopoulou, A. (2010). Knowing you care: effects of perceived empathy and attachment style on pain perception. Pain 151, 687-693. doi:10.1016/j. pain.2010.08.035

Schaefer, C., Coyne, J. C., and Lazarus, R. S. (1981). The health-related functions of social support. J. Behav. Med. 4, 381-406.

Schilbach, L., Timmermans, B., Reddy, V., Costall, A., Bente, G., Schlicht, T., et al. (in press). Toward a secondperson neuroscience. Behav. Brain Sci.

Schultz, W., and Dickinson, A. (2000). Neuronal coding of prediction errors. Annu. Rev. Neurosci. 23, 473-500. doi: 10.1146/annurev.neuro.23.1.473

Scott, D. J., Stohler, C. S., Egnatuk, C. M., Wang, H., Koeppe, R. A., and Zubieta, J.-K. (2007). Individual differences in reward responding explain placebo-induced expectations and effects. Neuron 55, 325-336. doi:10. 1016/j.neuron.2007.06.028

Seeley, W. W., Menon, V., Schatzberg, A. F., Keller, J., Glover, G. H., Kenna, H., et al. (2007). Dissociable intrinsic connectivity networks for salience processing and executive control. J. Neurosci. 27, 2349-2356. doi:10. 1523/JNEUROSCI.5587-06.2007

Seth, A. K., Suzuki, K., and Critchley, H. D. (2012). An interoceptive predictive coding model of conscious presence. Front. Psychol. 2:395. doi: 10.3389/fpsyg.2011.00395

Strathearn, L., Fonagy, P., Amico, J., and Montague, P. R. (2009). Adult attachment predicts maternal brain and oxytocin response to infant cues. Neuropsychopharmacology 34, 2655-2666. doi:10.1038/npp.2009. 103

Sullivan, M. J., Thorn, B., Haythornthwaite, J. A., Keefe, F., Martin, M., Bradley, L. A., et al. (2001). Theoretical perspectives on the relation between catastrophizing and pain. Clin. J. Pain 17, 52-64.

Sullivan, M. J. L., Adams, H., and Sullivan, M. E. (2004). Communicative dimensions of pain catastrophizing: social cueing effects on pain behaviour and coping. Pain 107, 220-226.

Sussman, N. M., and Rosenfeld, H. M. (1978). Touch, justification, and sex: influences of the aversiveness of spatial violations. J. Soc. Psychol. 106, 215-225. doi:10.1080/ 00224545.1978 .9924173

Sussman, N. M., and Rosenfeld, H. M. (1982). Influence of culture, language, and sex on conversational distance. J. Pers. Soc. Psychol. 42, 66-74. doi:10.1037/0022-3514.42.1.66

Tait, R. (2008). Empathy: necessary for effective pain management? Curr. Pain Headache Rep. 12, 108-112. doi 10.1007/s11916-008-0021-6

Tajfel, H. (1982). Social psychology of intergroup relations. Annu. Rev. Psychol. 33, 1-39. doi:10.1146/annurev. ps.33.020182.000245

Tracey, I., Ploghaus, A., Gati, J. S., Clare, S., Smith, S., Menon, R. S., et al. (2002). Imaging attentional modulation of pain in the periaqueductal gray in humans. J. Neurosci. 22, 2748-2752.

Uchino, B. N., Cacioppo, J. T., and Kiecolt-Glaser, J. K. (1996). The relationship between social support and physiological processes: a review with emphasis on underlying mechanisms and implications for health. Psychol. Bull. 119, 488-531.

Van Kleef, G. A. (2009). How emotions regulate social life: the emotions as social information (EASI) model. Curr. Dir. Psychol. Sci. 18, 184-188.

Vervoort, T., Caes, L., Trost, Z., Sullivan, M., Vangronsveld, K., and Goubert, L. (2011). Social modulation of facial pain display in highcatastrophizing children: an observational study in schoolchildren and their parents. Pain 152, 1591-1599. doi:10.1016/j.pain.2011.02.048

Vervoort, T., Goubert, L., Eccleston, C., Verhoeven, K., De Clercq, A., Buysse, A., et al. (2008). The effects of parental presence upon the facial expression of pain: the moderating role of child pain catastrophizing.
Pain 138, 277-285. doi:10.1016/j. pain.2007.12.013

Villemure, C., and Bushnell, M. C. (2002). Cognitive modulation of pain: how do attention and emotion influence pain processing? Pain 95, 195-199.

Vlaeyen, J. W. S., Hanssen, M., Goubert, L., Vervoort, T., Peters, M., van Breukelen, G., et al. (2009). Threat of pain influences social context effects on verbal pain report and facial expression. Behav. Res. Ther. 47, 774-782. doi:10.1016/j. brat.2009.05.008

Vrticka, P., and Vuilleumier, P. (2012). Neuroscience of human social interactions and adult attachment style. Front. Hum. Neurosci. 6:212. doi: 10.3389/fnhum.2012.00212

Waters, E., Merrick, S., Treboux, D., Crowell, J., and Albersheim, L. (2000). Attachment security in infancy and early adulthood: a twenty-year longitudinal study. Child Dev. 71, 684-689. doi:10.1111/ 1467-8624.00179

Weisse, C. S., Foster, K. K., and Fisher, E. A. (2005). The influence of experimenter gender and race on pain reporting: does racial or gender concordance matter? Pain Med. 6, 80-87. doi:10.1111/j.1526-4637. 2005.05004.x

Wiech, K., Lin, C.-S., Brodersen, K. H., Bingel, U., Ploner, M., and Tracey, I. (2010). Anterior insula integrates information about salience into perceptual decisions about pain. J. Neurosci. 30, 16324-16331.

Wiech, K., and Tracey, I. (2013). Pain, decisions and actions: a motivational perspective. Front. Neurosci. 7:46. doi:10.3389/fnins.2013.00046

Williams, A. C. (2002). Facial expression of pain: an evolutionary account. Behav. Brain Sci. 25, 439-455. doi: 10.1017/S0140525X02430087

Williams, S. E., Blount, R. L., and Walker, L. S. (2011). Children's pain threat appraisal and catastrophizing moderate the impact of parent verbal behavior on children's symptom complaints. J. Pediatr. Psychol. 36, 55-63. doi:10.1093/jpepsy/jsq043

Wilson, C. L., and Ruben, M. A. A. (2011). Pain in her arm: romantic attachment orientations and the tourniquet task. Pers. Relatsh. 18, 242-265. doi:10.1111/j.1475-6811. 2011.01359.x

Wood, P. B. (2006). Mesolimbic dopaminergic mechanisms and pain control. Pain 120, 230-234. doi: 10.1016/j.pain.2005.12.014

Yoshino, A., Okamoto, Y., Onoda, K., Yoshimura, S., Kunisato, Y., Demoto, Y., et al. (2010). Sadness enhances 
the experience of pain via neural activation in the anterior cingulate cortex and amygdala: an fMRI study. Neuroimage 50, 1194-1201. doi:10.1016/j.neuroimage.2009.11. 079

Younger, J., Aron, A., Parke, S., Chatterjee, N., and Mackey, S. (2010). Viewing pictures of a romantic partner reduces experimental pain: involvement of neural reward systems. PLoS
ONE 5:e13309. doi:10.1371/journal. pone.0013309

Yu, S. Q., Lundeberg, T., and Yu, L. C. (2003). Involvement of oxytocin in spinal antinociception in rats with inflammation. Brain Res. 983, 13-22.

Conflict of Interest Statement: The authors declare that the research was conducted in the absence of any commercial or financial relationships that could be construed as a potential conflict of interest.

Received: 27 March 2013; accepted: 04 July 2013; published online: 23 July 2013. Citation: Krahé C, Springer A, Weinman JA and Fotopoulou A (2013) The social modulation of pain: others as predictive signals of salience - a systematic review. Front. Hum. Neurosci. 7:386. doi: 10.3389/fnhum.2013.00386
Copyright (C) 2013 Krahé, Springer, Weinman and Fotopoulou. This is an open-access article distributed under the terms of the Creative Commons Attribution License, which permits use, distribution and reproduction in other forums, provided the original authors and source are credited and subject to any copyright notices concerning any third-party graphics etc. 